\title{
Global Dynamic Topography Observations Reveal Limited Influence of Large-Scale Mantle Flow
}

\author{
M. J. Hoggard*, N. White \& D. Al-Attar
}

April 28, 2016

\begin{abstract}
Bullard Laboratories, Department of Earth Sciences, University of Cambridge, Madingley Rise, Madingley Road, Cambridge, CB3 0EZ, UK. *email: mjh217@cam.ac.uk, njw10@cam.ac.uk
\end{abstract}

Convective circulation of the Earth's mantle maintains some fraction of surface topography that varies with space and time. Most predictive models show that this dynamic topography has peak amplitudes of $\pm 2 \mathbf{k m}$, dominated by wavelengths of $10^{4} \mathbf{k m}$. Here, we test these models against our comprehensive observational database of 2,120 spot measurements of dynamic topography that were determined by analysing oceanic seismic surveys. These accurate measurements have typical peak amplitudes of $\pm 1 \mathbf{~ k m}$ and wavelengths of approximately $10^{3} \mathbf{~ k m}$ and are combined with limited continental constraints to generate a global spherical harmonic model whose robustness has been carefully tested and benchmarked. Our power spectral analysis reveals significant discrepancies between observed and predicted dynamic topography. At longer wavelengths (such as $10^{4} \mathbf{~ k m}$ ), observed dynamic topography has peak amplitudes of $\pm 500 \mathrm{~m}$. At shorter wavelengths (such as $10^{3} \mathbf{~ k m}$ ), significant dynamic topography is still observed. We show that these discrepancies can be explained if short-wavelength dynamic topography is generated by temperature-driven density anomalies within a sub-plate asthenospheric channel. Stratigraphic observations from adjacent continental margins show that these dynamic topographic signals evolve quickly with time. More rapid temporal and spatial changes in vertical displacement of the Earth's surface have direct consequences for fields as diverse as mantle flow, oceanic circulation and long-term climate change.

Topography and bathymetry at the Earth's surface are isostatically maintained by variations in the thickness and density of crust and lithospheric mantle. Thus mountain belts have thicker crust whereas depressions have thinner crust. In the oceanic realm, subsidence away from midoceanic ridges is dominated by cooling and thickening of the lithospheric plate. Nevertheless, it is generally recognised that some fraction of topography and bathymetry are controlled by a changing pattern of convective circulation within the underlying mantle ${ }^{1}$. Spatial and temporal patterns of this dynamic topography contain useful clues about the fluid mechanical properties of the convecting interior ${ }^{2}$. Pekeris ${ }^{1}$ showed that, within a convecting Earth, normal stresses generated by internal flow act to deform the Earth's surface. Later, Richards and Hager ${ }^{3}$ demonstrated that surface deflections and geoid variations are produced by lateral density anomalies within the mantle. In both cases, the response kernels (i.e. Green's functions) depend on the assumed radial viscosity structure of the mantle.

Agreement between observed and predicted geoid anomalies for spherical harmonic degrees $l=2-6$ (i.e. wavelengths of $16,000-6,000 \mathrm{~km}$ ) is obtained using a density model estimated 
by assuming that seismic anomalies within the lower mantle have a thermal origin ${ }^{4,5,6}$. For an acceptable range of radial viscosity functions, this density model predicts long-wavelength dynamic topographic anomalies with amplitudes of $\pm 1 \mathrm{~km}$ at wavelengths corresponding to $l=$ $2-3^{4}$. Although the paradox that long-wavelength positive density anomalies within the lower mantle correlate with negative geoid anomalies was resolved if the lower mantle is ten times more viscous than the upper mantle, detailed observations were unavailable to test predicted patterns of dynamic topography.

Subsequent studies have explored complementary approaches for inferring mantle density structure which is then used to match long-wavelength geoid anomalies and to predict dynamic topography. For example, some instantaneous flow models exploit present-day mantle densities inferred from global seismic tomography ${ }^{7,8}$. Other models are based upon time-integrated histories of Phanerozoic plate subduction ${ }^{9,10}$. More controversially, time-dependent convective simulations of present-day density structures have been carried out using forward, backward and adjoint methods ${ }^{11,12,13}$. Despite increasing levels of computational complexity, these different models yield broadly similar dynamic topographic patterns, dominated by $l=2-6$ with peak amplitudes of $1-3 \mathrm{~km}$ and root-mean-squared (rms) amplitudes of $0.5-1.0 \mathrm{~km}^{10}$.

\section{Global Residual Depth Measurements}

Our goal is to develop an accurate spherical harmonic model of observed dynamic topography. Identifying dynamic topography is complicated by the need to separate it from isostatic topography generated by thickness and density contrasts within the lithospheric plates. Cooling and thickening of oceanic lithosphere generate a predictable relationship for subsidence as a function of age ${ }^{14}$. If the effects of plate cooling, loading and flexure are accurately removed, residual depth anomalies are isolated that can be regarded as proxies for oceanic dynamic topography ${ }^{15}$. A new database comprising 1,124 seismic reflection profiles, 191 seismic wide-angle (i.e. waveform-modelled) experiments, and 341 vintage seismic refraction (i.e. slope-interceptmodelled) experiments has been compiled (Figure 1a). This database provides comprehensive coverage of the oceanic realm with a bias toward the oldest oceanic crust that abuts continental margins. Regions where flexural bending and large amplitude but short-wavelength free-air gravity anomalies exist have been excluded (Supplementary Information).

On each image, bona fide oceanic crust is identified from its characteristic acoustic architecture and magnetic anomaly pattern ${ }^{17}$. On seismic reflection profiles, the sediment-basement interface is usually clear whilst the base of the crust (i.e. Moho) often consists of a single bright reflection (Figure 2a-c). Reliability of crustal models determined from reversed seismic wide-angle and refraction experiments depends upon vintage of the experiment and upon modelling technique. Optimal results come from modern, densely sampled experiments where observed and calculated travel times and waveforms are matched by forward or inverse modelling. It is important that the horizontal range of these experiments is great enough to observe diving waves turning within the upper mantle. Older refraction experiments analysed using slope-intercept methods typically underpredict true crustal thickness by $\sim 20 \%^{18}$. We measured water-loaded oceanic residual depth anomalies using a well-established approach ${ }^{19,20,21}$. Two isostatic corrections allow for variable sedimentary and crustal loading (Methods). Accuracy of the sedimentary correction depends upon calibration between two-way travel time and depth, which is obtained from 43 locations where seismic reflection and wide-angle surveys intersect. Observed crustal thicknesses are used to determine the crustal correction which assumes a reference crustal thickness of $7.1 \mathrm{~km}$ and a reference density of $2.86 \mathrm{Mg} \mathrm{m}^{-3}$. Crustal age is 

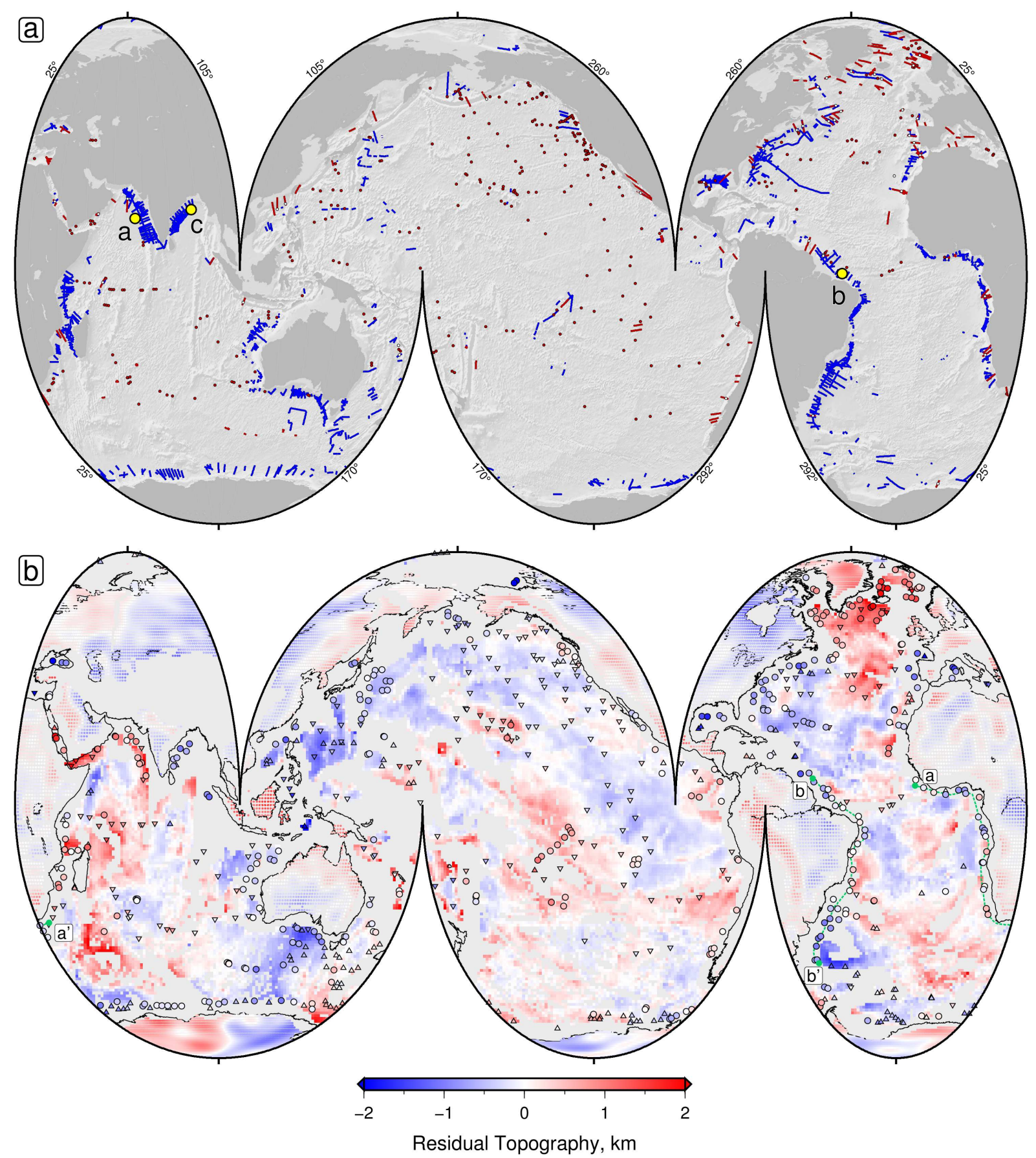

Figure 1: Maps of seismic and residual topographic databases. (a) Segmented Mollweide projection of global bathymetry sampled every $0.25^{\circ}$. Blue lines $=1,164$ legacy seismic reflection profiles; red lines $=191$ waveform-modelled seismic wide-angle experiments; red circles $=$ locations of 341 slope-intercept modelled seismic wide-angle experiments; yellow circles $=$ three seismic reflection images shown in Figure 2; small white circles $=43$ intersections between reflection profiles and wide-angle seismic experiments used to calibrate the sedimentary correction. (b) Residual topographic measurements sampled in $4^{\circ}$ bins (red/blue $=$ positive/negative) . Circles $=$ measurements with sedimentary and crustal corrections; upward/downward pointing triangles = measurements with lower/upper limits only; offshore grid $=$ residual topography estimated from edited ship-track database, sampled every $1^{\circ}$; onshore grid $=$ residual topography calculated by scaling long-wavelength $(>700 \mathrm{~km})$ free-air gravity anomalies sampled every $1^{\circ}$ using an admittance, $Z=50 \mathrm{mGal} / \mathrm{km}^{16}$; green dashed lines labelled $\mathrm{a}-\mathrm{a}^{\prime}$ and $\mathrm{b}-\mathrm{b}^{\prime}=$ transects shown in Figure 3. 
determined from the pattern of magnetic anomalies ${ }^{17}$.

Resultant water-loaded depths to basement can be compared with a revised global oceanic age-depth relationship ${ }^{22}$. This relationship is preferable since it is based upon a global observational database from which anomalous oceanic crust and regions of dynamic topography were excised. We obtain similar results when alternative age-depth relationships are used (Supplementary Information). Most residual topography anomalies fall within $\pm 1 \mathrm{~km}$ of the expected age-depth relationship with a mean value of $-60 \mathrm{~m}$ and a standard deviation of $\sim 700 \mathrm{~m}$. Positive anomalies tend to be associated with the youngest crust close to mid-oceanic ridges and negative anomalies occur within the oldest oceanic basins (Figure 2d). Positive anomalies with amplitudes of 1-2 km and wavelengths as great as $2500 \mathrm{~km}$ occur in the vicinity of the Icelandic, Hawaiian, Azorean and Afar plumes (Figure 1b). Similarly large negative anomalies occur along the east coast of North America, in the Gulf of Mexico, and between Australia and Antarctica.

Offshore West Africa, several cycles of smoothly varying residual topographic anomalies are observed (Figure 3a). Anomalies are negligible at the northern end of this transect before decreasing to $-800 \mathrm{~m}$ at the Guinea Abyssal Plain. The Cameroon Volcanic Line sits on top of an elongated swell with a positive anomaly of up to $+900 \mathrm{~m}$. This anomaly decreases southwards to $-1 \mathrm{~km}$ offshore Gabon. A second cycle steadily rises to $+800 \mathrm{~m}$ at the offshore expression of the Angolan Dome. Different patterns of anomalies are observed along the Brazilian margin (Figure 3b). Notably, the Argentine abyssal plain is characterised by a $\sim 2000 \mathrm{~km}$ wide negative anomaly which is probably one of the largest convective drawdowns on Earth ${ }^{23}$.

These long-wavelength anomalies cannot be maintained by lithospheric flexure but are generated by convective circulation. The match between our measurements and long-wavelength free-air gravity anomalies suggests that the gravity field is a reasonable proxy for dynamic topography elsewhere. Existence of these anomalies is corroborated by independent geological constraints which also demonstrate that they evolve rapidly with time. For example, the position of the Angolan Dome, which has a diameter of $1000 \mathrm{~km}$ and an amplitude of $+800 \mathrm{~m}$, coincides with evidence for $\sim 500 \mathrm{~m}$ of post-Pliocene uplift estimated from truncation of deltaic topset deposits along the continental shelf ${ }^{24}$. The adjacent coastline is characterised by emergent marine terraces that record Quaternary uplift rates of $0.3 \mathrm{~mm} \mathrm{yr}^{-125}$. Both observations are consistent with an uplift rate history calculated from inverse modelling of river profiles that radially drain the Angolan Dome ${ }^{26}$.

\section{Spherical Harmonic Analysis}

In the oceans, spot measurements are supplemented with conservatively edited grids of residual depth measurements. Water depths were measured from ship-track bathymetry ${ }^{27}$. Sedimentary corrections were calculated using global digital grids ${ }^{28,29}$. These grids have significant errors along continental margins and so we have excised regions where sediment is thicker than $1.5 \mathrm{~km}$. Areas of anomalously thin/thick crust were also conservatively excised (e.g. seamounts, plateaux, fracture zones, flexural moats; Supplementary Information). At their intersections, spot and ship-track derived measurements generally match.

To generate a global spherical harmonic model of observed dynamic topography, more limited continental constraints are included. Attempts to constrain continental dynamic topography are complicated by variable lithospheric architecture ${ }^{30}$. Here, we have exploited two different strategies. Continental dynamic topography can be isostatically gauged using thickness and density measurements taken from the global CRUST1.0 database (Supplementary Informa- 



Figure 2: Images of oceanic crust. (a) Seismic reflection profile of $59 \mathrm{Ma}$ oceanic crust (west of India). $\mathrm{S}=$ seabed; $\mathrm{B}=$ sediment-basement interface; $\mathrm{M}=$ Moho (i.e. base of crust); TWTT = two-way travel time. (b) $92 \mathrm{Ma}$ oceanic crust (offshore Brazil). (c) 110 Ma oceanic crust (east of India). Crustal ages from magnetic reversal history ${ }^{17}$. Images shown courtesy of ION. (d) Black symbols $=2,120$ agedepth measurements from seismic reflection/wide-angle experiments plotted as function of plate age; solid line $=$ age-depth relationship of Crosby and McKenzie ${ }^{22}$; dashed lines $= \pm 1 \mathrm{~km}$ either side of age-depth relationship; Labelled coloured circles $=$ age-depth measurements calculated from above three profiles, where colour $=$ amplitude of residual depth anomaly (scale on Figure 1). Error bars represent $1 \sigma$ uncertainties (Methods). 

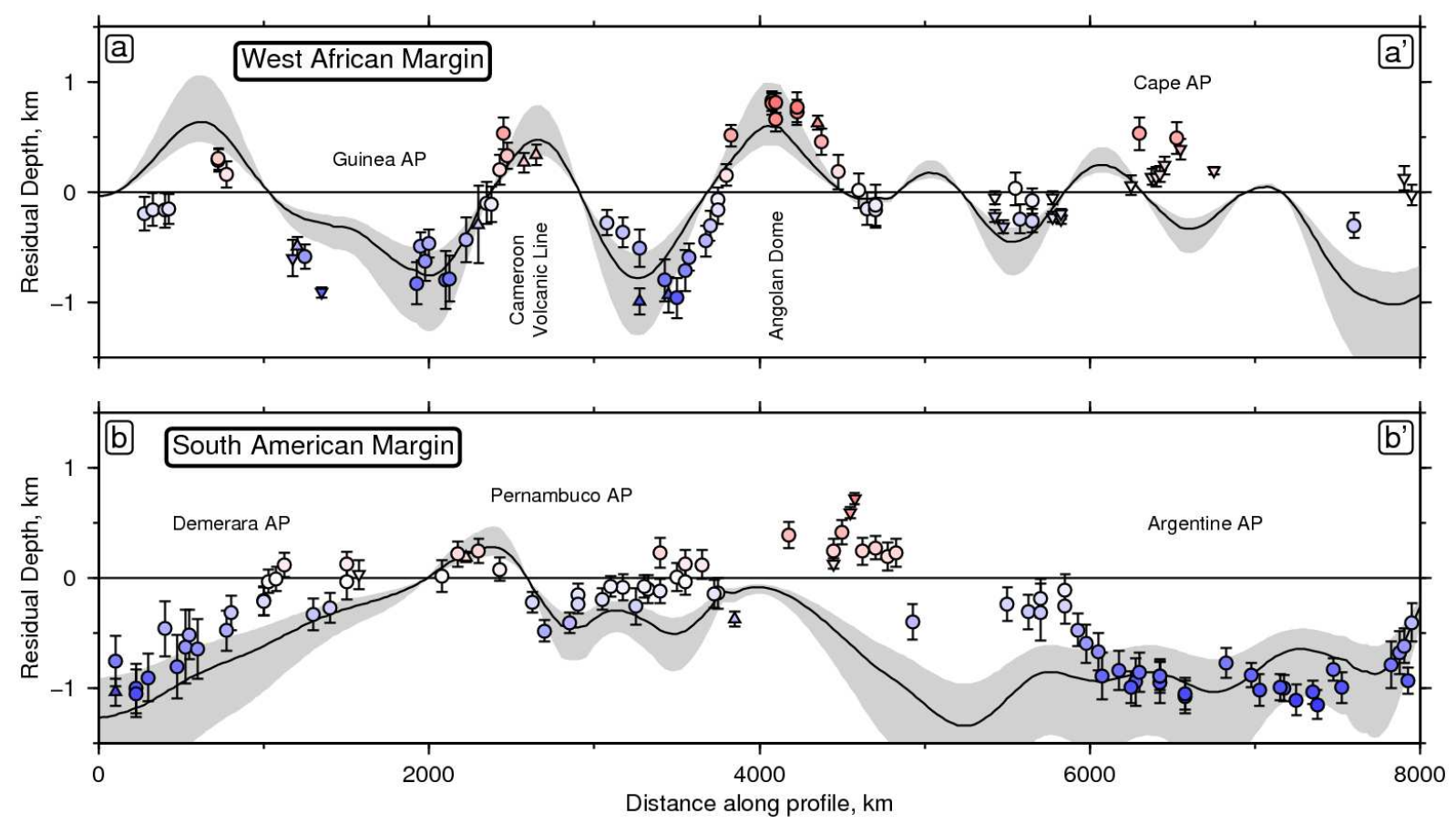

Figure 3: Transects along oldest oceanic crust of South Atlantic margins. (a-a') West African margin. Coloured circles/triangles $=$ residual depth measurements averaged within $1^{\circ}$ bins with one $\sigma$ uncertainty located within $80 \mathrm{~km}$ of transect; black line with grey band = dynamic topography calculated from long-wavelength (700-9,000 km) free-air gravity anomalies using $Z=25 \pm 10 \mathrm{mGal} / \mathrm{km}$; AP = Abyssal Plain. (b-b') South American margin. Both transects are approximately perpendicular to plate-spreading flowlines.

tion). However, since our oceanic analyses show that free-air gravity anomalies are a reliable proxy, we prefer to seed continents with estimates of dynamic topography that are based upon the coherence between long-wavelength gravity anomalies, topography and drainage patterns. First, the GRACE gravity field was low-pass filtered to remove wavelengths shorter than about $700 \mathrm{~km}$ (i.e. $l=55)^{31}$. Secondly, these long-wavelength anomalies were scaled by assuming a constant air-loaded admittance of $Z=50 \mathrm{mGal} \mathrm{km}^{-1}$. We have also tested the effects of using different values and functional forms of $Z$ (Supplementary Information) ${ }^{16,32}$. Thirdly, anomalies which occur within $500 \mathrm{~km}$ of oceanic residual depth measurements were removed. We excised all active orogenic belts and zones of flexural bending (Supplementary Information). The reliability of the remaining gravity anomalies is checked by plotting drainage networks and hotspot volcanism which typically show that radial drainage occurs away from positive anoma$\operatorname{lies}^{26}$. The combined offshore and onshore database is shown in Figure 1b. This approach is reliable for Africa, Arabia, western North America and eastern Australia where long-wavelength gravity anomalies and topography correlate ${ }^{26,33,34,35}$.

We have fitted spherical harmonic functions to this global database using a regularised least squares inversion algorithm (Methods). Figure 4a shows a damped model that was fitted up to, and including, $l=30$. This model yields a residual misfit of $\chi^{2} \sim 1$ (Figure 5a). If lower degree models are used to fit the global database, $\chi^{2}$ is substantially larger (e.g. $\chi^{2} \sim 8$ for an $l=2$ model). These results imply that it is necessary to include shorter wavelength functions in order to adequately fit the observational database. If only accurate spot measurements are used, $\chi^{2}$ is larger, suggesting that higher degree structure is present. The robustness of our inverse 

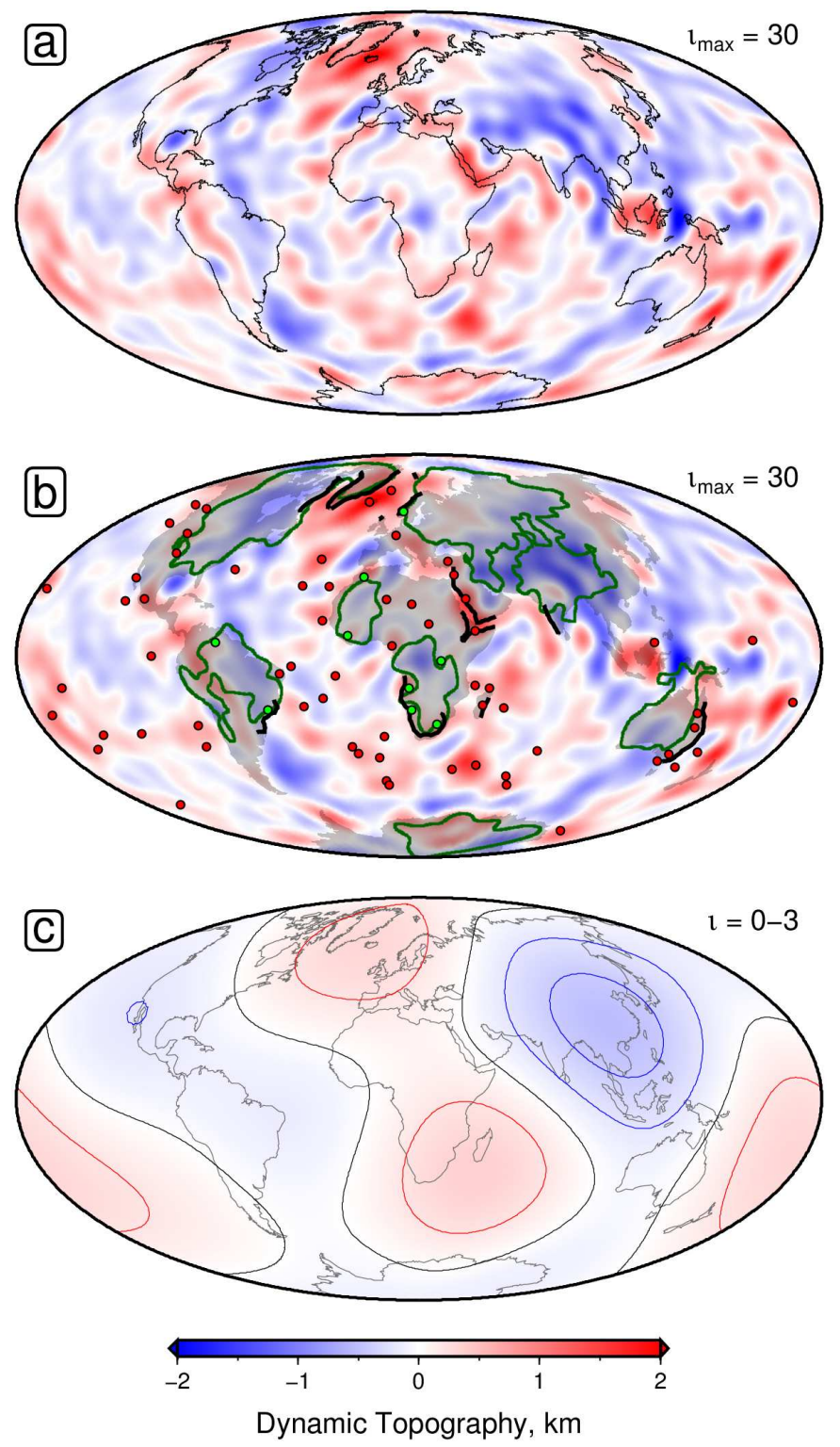

Figure 4: Observed dynamic topography. (a) Spherical harmonic model up to $l=30$ of measurements shown in Figure 1b. (b) Model overlain with other geological/geophysical observations. Green polygons $=$ continental lithosphere $>150 \mathrm{~km}_{\text {thick }}{ }^{36}$; red/green circles = magmatic/amagmatic topographic swells with radial drainage patterns (Supplementary Information); black lines = prominent anorogenic escarpments. (c) $l=0-3$ components of spherical harmonic model. Contour lines every $200 \mathrm{~m}$; black line $=$ zero contour.

method has been tested by carrying out a battery of checkerboard tests, damping parameter sweeps, and spatial coverage analyses (Supplementary Information). We have also carefully tested the consequences of using alternative age-depth models. Crucially, if the CRUST1.0 database is used to calculate continental dynamic topography, or if continents are completely excluded, the resultant spectra are practically identical (Supplementary Figure S3).

Our global model is consistent with independent geological observations. Active hotspot volcanism, radial drainage patterns, and prominent escarpments all occur in regions of positive dynamic support and often coincide with embayments into thick cratonic lithosphere (Figure 4b). The longest wavelength components of our spherical harmonic model (i.e. $l=0-3$ ) 



Figure 5: Residual misfit and power spectra. (a) Residual misfit, $\chi^{2}$, plotted as function of maximum degree, $l_{\max }$, used to fit observations (Figure 1b). Solid circles $=\chi^{2}$ values from fitting combined offshore/onshore global database of dynamic topographic observations; open circles $=\chi^{2}$ values from fitting spot measurements from oceanic realm alone. Corresponding wavelengths, $\lambda$, are shown at the top. (b) Black solid line = power spectrum obtained by regularised least squares inversion of global database of dynamic topography observations; dotted lines = uncertainty resulting from range of gradient regularisation and amplitude damping coefficients $\left(10^{-0.5}-10^{+0.5}\right.$ and $10^{2}-10^{3}$, respectively); thin line with grey bounds = mean and standard deviation of power spectra for five predictive models of dynamic topography $7,8,9,10,13$.

broadly agree with the pattern of geoid anomalies (Figure 4c). For example, positive anomalies occur over the Icelandic plume, over sub-equatorial Africa, and over the west Pacific Ocean. Negative anomalies occur over southeast Asia, over equatorial South America, and over western North America. Amplitudes of these long-wavelength anomalies are significantly smaller than those predicted by most models. The rms amplitude for $l=0-3$ is $170 \mathrm{~m}$ with peaks of $-515 \mathrm{~m}$ and $+373 \mathrm{~m}$. A typical predictive model has an rms amplitude of $648 \mathrm{~m}$ with peaks of $-1658 \mathrm{~m}$ and $+1664 \mathrm{~m}$ for $l=0-3^{10}$. 


\section{Geodynamical Consequences}

Power spectral analyses of our observations and of predictive models reveal significant differences (Figure 5b). Predictive models are spectrally red with a prominent peak at $l=2$. In contrast, the observed spectrum has one order of magnitude less power at $l=2$ with much greater power at $l=20-30$. Significantly, the slope of this spectrum matches Kaula's Rule, even when continental observations are excluded (Supplementary Information). Differences between these observed and predicted spectra yield new and important insights into the nature of mantle convection. If viscosity varies as a function of radius alone, Hager and Richards ${ }^{37}$ showed that the geoid and dynamic topography at the Earth's surface can be calculated from

$$
\delta N^{l m}=\frac{4 \pi G a}{g(2 l+1)} \int_{r}^{a} G^{l}(r) \delta \rho^{l m}(r) d r
$$

and

$$
\delta a^{l m}=\frac{1}{\Delta \rho_{a}} \int_{r}^{a} A^{l}(r) \delta \rho^{l m}(r) d r
$$

where $\delta N^{l m}$ is the geoid height and $\delta a^{l m}$ is deflection of the Earth's surface. $g$ is acceleration due to gravity and $\Delta \rho_{a}$ is the density difference between mantle and water (or air). $G^{l}(r)$ and $A^{l}(r)$ are normalised geoid and surface response kernels as a function of radius, $r$, for a density anomaly located at different depths within the mantle. Finally, $\delta \rho^{l m}(r)$ represents mantle density anomalies. Superscripts $l$ and $m$ refer to spherical harmonic degree and order, respectively (Methods). Predicted geoid and dynamic topography depends upon viscosity structure and upon the distribution of mantle density anomalies. Figures $6 \mathrm{c}$ and $6 \mathrm{~d}$ show how $G^{l}(r)$ and $A^{l}(r)$ vary with degree for a typical radial viscosity function ${ }^{38}$.

Mantle density anomalies are computed directly from seismic tomographic models by scaling shear wave velocity anomalies. It is generally accepted that temperature variations are the dominant control although compositional variations play some role e.g. ${ }^{5,6,39}$. A useful rule of thumb is to multiply shear wave velocity anomalies by $0.2\left(\mathrm{Mg} \mathrm{m}^{-3}\right)\left(\mathrm{km} \mathrm{s}^{-1}\right)^{-1}$. Forte ${ }^{39}$ analysed a suite of six global tomographic models and used a range of scaling factors to calculate the average magnitude of density anomaly as a function of radius (Figure 6e). Lateral density variations are important within the top $1000 \mathrm{~km}$ and bottom $1000 \mathrm{~km}$ of the mantle, reflecting the distribution of shear wave velocity anomalies.

Geoid variations and dynamic topography are calculated by convolving response kernels with density profiles (Figure 6c-e). Since the observed velocity (and inferred density) structure of the whole mantle are dominated by $l=2$, calculated water-loaded dynamic topography has an amplitude of $1.5 \pm 0.4 \mathrm{~km}$, in accordance with the suite of predicted power spectra shown in Figure 5b. This value is much larger than the $l=0-3$ components of the observed dynamic topography model which have an amplitude range of $888 \mathrm{~m}$ (Figure 4c). To isolate the source of this discrepancy, we divide the problem into two parts. First, consider the lower mantle where the response kernel is non-negligible for only the smallest degrees. At $l=2$, density anomalies between $1500 \mathrm{~km}$ depth and the core-mantle boundary generate $179 \pm 63 \mathrm{~m}$ of dynamic topography. This value matches our observations and suggests that the lower mantle contributes modestly to dynamic topography ${ }^{41}$. At $l=2$, positive lower mantle density anomalies generate geoid anomalies of $-31 \pm 10 \mathrm{~m}$, which agrees with the observed geoid ${ }^{4}$. Since response kernels for $l=8-30$ in the lower mantle are nearly zero, short-wavelength density anomalies at these depths cannot generate either surface deformation or geoid anomalies.

We now turn our attention to the upper half of the mantle where the shear wave spectrum is dominated by long wavelengths (Figure 6f). If inferred density anomalies are predominantly at 



Figure 6: Viscosity, velocity and density structure of mantle. (a) Schematic mantle structure as function of depth. D" refers to a layer of variable thickness located at the boundary between the core and mantle. (b) Radial viscosity structure ${ }^{38}$. (c) Normalised geoid kernels and (d) normalised surface deformation kernels, calculated from radial viscosity structure shown in (b), for $l=2,8$ and $30^{38}$. (e) Average radial density anomaly relative to PREM, calculated from a set of six shear wave tomographic models ${ }^{39}$. Dotted lines $=$ one standard deviation. (f) Power of shear wave velocity anomalies as function of depth and degree for S40RTS tomography model ${ }^{40}$.

$l=2$, the amplitude of calculated dynamic topography is $1.36 \pm 0.29 \mathrm{~km}$. Note that many predictive models omit the outer $\sim 300 \mathrm{~km}$ of the mantle and lithosphere ${ }^{10}$. This omission reduces the amplitude of calculated dynamic topography to $0.48 \pm 0.13 \mathrm{~km}$ at $l=2$. There are three reasons for omitting the uppermost mantle. First, the density of crossing rays is greatly reduced near the Earth's surface, smearing out body wave tomographic models. Secondly, compositional variations beneath mid-oceanic ridges and within the continental lithosphere complicate this velocity-to-density conversion. Thirdly, the value of the surface response kernel, $A^{l}(r)$, rapidly approaches unity, leading to unrealistically large values of dynamic topography. If, instead, the upper mantle is dominated by density anomalies of $l=30$, the predicted dynamic topography is $0.86 \pm 0.14 \mathrm{~km}$ with a negligible geoid anomaly, in close agreement with our observed dynamic topography and with geoid anomalies. A simple way of resolving the discrepancy is to infer $l=30$ density anomalies within the upper half of the mantle and $l=2$ anomalies within the lower half. In this instance, the $l=2$ component of dynamic topography is $179 \pm 63 \mathrm{~m}$ and the $l=30$ component is $864 \pm 142 \mathrm{~m}$. Thus distributing density anomalies at low degrees in the lower mantle and at higher degrees in the upper mantle better matches both the geoid and observed dynamic topography. This bimodal distribution may also explain why negative admittance is so rarely observed on Earth (Figure 2 from Colli et al. ${ }^{32}$ ).

The existence of significant observed power at $l=10-30$ underlines the importance of shallow, short-wavelength mantle density structure, which is supported by independent observations $^{42}$. Beneath the North Atlantic Ocean, a $150 \pm 50 \mathrm{~km}$ low velocity layer has been seismically imaged ${ }^{43,44}$. Short-wavelength temperature perturbations generated within a major convective upwelling centred beneath Iceland flow radially within this layer ${ }^{45,46}$. Globally, there is increasing seismic and geochemical evidence for sub-plate asthenospheric channels $44,47,48,49$. To generate dynamic topography, the required temperature perturbation, $\Delta T$, within a channel is given by

$$
\Delta T=\frac{U\left(1-\alpha T_{\circ}\right)}{h \alpha}
$$

where $U$ is the air-loaded dynamic topography in $\mathrm{km}, \alpha=3.3 \times 10^{-5}{ }^{\circ} \mathrm{C}^{-1}$ is the thermal expansion coefficient, $T_{\circ}=1300^{\circ} \mathrm{C}$ is the background temperature of the asthenosphere, 
and $h \mathrm{~km}$ is the channel thickness (Supplementary Information) ${ }^{46}$. The amplitude of waterloaded dynamic topography is $\pm 1 \mathrm{~km}$ which represents an air-loaded equivalent of $\pm 0.7 \mathrm{~km}$. If $h=150 \pm 50 \mathrm{~km}$, we obtain $\Delta T \sim 150 \pm 50^{\circ} \mathrm{C}$, consistent with the range of asthenospheric temperatures inferred from geochemical analysis of basaltic rocks at mid-oceanic ridges, from oceanic crustal thicknesses, and from convective circulation models ${ }^{18,49,50,51}$.

\section{Implications for Mantle Dynamics and Surface Systems}

We present a new and comprehensive global database of oceanic residual depth measurements which was carefully constructed by analysing substantial inventories of seismic reflection, modern wide-angle and legacy refraction profiles. Residual depth anomalies have amplitudes of $\pm 1 \mathrm{~km}$ and wavelengths of $10^{3} \mathrm{~km}$. We combined our database of residual depths with sparser continental constraints to build a globally continuous model. Spectral analysis shows there is one order of magnitude less power at the longest wavelengths and significantly more power at shorter wavelengths than suggested by existing predictive models. This discrepancy holds true when only the most robust observations from the oceanic realm alone are analysed.

Our new results have two significant implications. First, it is likely that shallow mantle convection exerts a significant role in generating and maintaining dynamic topography. An important corollary is that existing global seismic tomographic models of the upper mantle do not currently resolve short-wavelength density anomalies. Secondly, the ubiquity of observed short-wavelength dynamic topography implies that the planform of mantle convection evolves more rapidly than previously imagined.

Our observations provide new constraints for calculating mantle density and viscosity structure that will have an immediate impact on studies concerning mantle fluid dynamics (e.g. glacial-isostatic adjustment, true polar wander). Furthermore, transient vertical motions on short length and timescales have profound consequences for subjects as diverse as the reconstruction of ancient oceanic currents, long-term climate, fluvial geomorphology and sedimentary routing systems. 


\section{Methods}

\section{Residual Depth Calculation}

Residual depth, $z_{r}$, is the difference between the expected depth to water-loaded oceanic basement, $z_{w}$, obtained from age-depth analysis of oceanic lithosphere unaffected by dynamic topography, and the observed depth to oceanic basement, $z_{o}{ }^{15}$. Thus

$$
z_{r}=z_{w}-z_{o}-C_{s}-C_{c}
$$

where $C_{s}$ and $C_{c}$ are sedimentary and crustal loading corrections, respectively.

\section{Age-Depth Analysis}

$z_{w}$ is obtained from a global age-depth analysis of oceanic lithosphere unaffected by dynamic topography ${ }^{22}$. Long-wavelength free-air gravity anomalies and ship-track bathymetric inventories were used to identify and remove regions where significant positive and negative dynamic topography occurs and where oceanic crust is anomalously thick or thin ${ }^{14}$. This relationship has been revised to remove sharp discontinuities and to account for the effects of cooling by hydrothermal circulation at mid-oceanic ridges.

$$
z_{w}(t)=\left\{\begin{array}{cl}
2850 & 0 \leq t<1 \\
2652+324 \sqrt{t} & 1 \leq t \leq 73 \\
5028+5.26 t-250 \sin \left(\frac{t-75}{30}\right) & 73<t \leq 156 \\
5750 & t>156
\end{array}\right.
$$

where $t$ is the plate age in millions of years and $z_{w}$ is the water-loaded depth to top of oceanic basement in metres. In addition to exploiting the age-depth relationship shown in Equation (5), we have also tested previously published age-depth relationships as well as both half-space cooling and plate models calculated directly from our observational database (Supplementary Information).

\section{Sedimentary and Crustal Corrections}

Variable sedimentary loads are converted into equivalent water loads using

$$
C_{s}=\left(\frac{\rho_{a}-\bar{\rho}_{s}}{\rho_{a}-\rho_{w}}\right) z_{s}
$$

where $z_{s}$ is the thickness of the sedimentary layer, $\rho_{a}=3.20 \pm 0.02 \mathrm{Mg} \mathrm{m}^{-3}$ is the density of asthenosphere, $\bar{\rho}_{s}$ is the average density of the sedimentary layer, and $\rho_{w}=1.03 \pm 0.01 \mathrm{Mg} \mathrm{m}^{-3}$ is the density of water. In the absence of borehole penetrations, $z_{s}$ and $\bar{\rho}_{s}$ are calculated from measurements of the two-way travel time of the sedimentary layer, $t_{s}$, using a global empirical database assembled from seismic reflection and wide-angle datasets shown in Figure 1a.

Sedimentary porosity, $\phi\left(z_{s}\right)$, is assumed to vary as a function of $z_{s}$ according to

$$
\phi\left(z_{s}\right)=\phi_{\circ} \exp \left(\frac{-z_{s}}{\lambda}\right)
$$


where $\phi_{\circ}$ and $\lambda$ are the initial porosity and compaction decay length, respectively. The sonic velocity of the sedimentary layer, $v$, is given by

$$
\frac{1}{v}=\frac{\phi}{v_{w}}+\frac{1-\phi}{v_{s g}}
$$

where $v_{s g}=5.50 \pm 0.50 \mathrm{~km} \mathrm{~s}^{-1}$ is the velocity of solid quartz grains and $v_{w}=1.50 \pm$ $0.01 \mathrm{~km} \mathrm{~s}^{-1}$ is the velocity of water. It is straightforward to determine the relationship between $t_{s}$ and $z_{s}$ so that

$$
\frac{t_{s}}{2}=\frac{z_{s}}{v_{s g}}+\phi_{\circ} \lambda\left(\frac{1}{v_{w}}-\frac{1}{v_{s g}}\right)\left[1-\exp \left(\frac{-z_{s}}{\lambda}\right)\right]
$$

The best fit between Equation 9 and the global empirical database is obtained for $\phi_{\circ}=0.6 \pm 0.1$ and $\lambda=3.9 \pm 1.1 \mathrm{~km}$ for $v_{s g}=5.50 \mathrm{~km} \mathrm{~s}^{-1}$. A Monte Carlo approach can be used to investigate how uncertainties in $\phi_{0}, \lambda$, and $v_{s g}$ propagate into uncertainties in $C_{s}$. The value of $\bar{\rho}_{s}$ is given by

$$
\bar{\rho}_{s}\left(z_{s}\right)=\rho_{s g}+\frac{\phi_{\circ} \lambda}{z_{s}}\left(\rho_{w}-\rho_{s g}\right)\left[1-\exp \left(\frac{-z_{s}}{\lambda}\right)\right]
$$

where $\rho_{s g}=2.65 \pm 0.05 \mathrm{Mg} \mathrm{m}^{-3}$ is the density of solid quartz grains. This empirical approach enables $z_{s}, \bar{\rho}_{s}$ and $C_{s}$ to be estimated for each seismic reflection image.

A smaller crustal correction, $C_{c}$, is estimated in two steps. First, two-way travel time is converted into crustal thickness, $z_{c}$, using an average crustal velocity of $\bar{v}_{c}=6.28 \pm 0.34 \mathrm{~km}$ $\mathrm{s}^{-1}$. Secondly, $z_{c}$ is normalised to the global average value of $7.1 \mathrm{~km}^{18}$. This yields

$$
C_{c}=\left(\frac{\rho_{a}-\bar{\rho}_{c}}{\rho_{a}-\rho_{w}}\right)\left(z_{c}-7.1\right)
$$

where $\bar{\rho}_{c}=2.86 \pm 0.03 \mathrm{Mg} \mathrm{m}^{-3}$ is the average crustal density.

\section{Spherical Harmonic Analysis}

The observational database consists of spot measurements of dynamic topography, $d_{i}$, at a set of colatitudes, $\theta_{i}$, and longitudes, $\varphi_{i}$, for $i=1, \ldots, N$. It is assumed that these data are subject to zero-mean, uncorrelated, Gaussian random errors where variance of the $i$ th datum is $\sigma_{i}^{2}$.

To investigate the spectral properties of this database, we seek an interpolating function, $f(\theta, \varphi)$, taking the form

$$
f(\theta, \varphi)=\sum_{l=1}^{L} \sum_{m=-l}^{l} f_{l m} \mathcal{Y}_{l m}(\theta, \varphi)
$$

such that $f\left(\theta_{i}, \varphi_{i}\right) \approx d_{i}$ at each spot measurement. Here, the $\mathcal{Y}_{l m}$ are fully normalised real spherical harmonics where $l$ is the degree and $m$ is the order. $L$ is the maximum spherical harmonic degree used in the expansion. We note that degree-zero contributions to the interpolating function have been excluded in accordance with physical constraints on dynamic topography. Given this interpolating function, the associated power at each value of $l$ is given by

$$
P_{l}=\sum_{m=-l}^{l} f_{l m}^{2}
$$


To determine the appropriate expansion coefficients, $f_{l m}$, in Equation (12), we use a regularised least squares misfit

$$
J=\frac{1}{2} \sum_{i=1}^{N} \frac{1}{\sigma_{i}^{2}}\left[f\left(\theta_{i}, \varphi_{i}\right)-d_{i}\right]^{2}+\frac{1}{2} \int_{\mathbb{S}^{2}}\left[\lambda_{1}\left\|\nabla_{1} f\right\|^{2}+\lambda_{2} f^{2}\right] \mathrm{d} S
$$

where $\lambda_{1}$ and $\lambda_{2}$ are non-negative weighting factors, $\mathbb{S}^{2}$ denotes the unit two-sphere, and $\nabla_{1}$ is the tangential gradient operator. The first term on the right-hand side of Equation (14) is proportional to

$$
\chi^{2}=\frac{1}{N} \sum_{i=1}^{N} \frac{1}{\sigma_{i}^{2}}\left[f\left(\theta_{i}, \varphi_{i}\right)-d_{i}\right]^{2}
$$

which determines how well the interpolating function fits observations. The second term acts to regularise the problem towards smooth interpolating functions and the third term damps the average amplitude of the model. In the absence of regularisation, the least squares problem has a unique solution only when there are more data points than expansion coefficients. However, by under-parameterising we could potentially neglect geologically significant short-wavelength features. Instead, it is preferable to exploit a combination of gradient regularisation to remove spurious short-wavelength features and amplitude damping to maintain realistic values of dynamic topography in unconstrained regions. In practice, this amplitude damping is only important beneath the excised Himalayan orogenic belt.

To obtain a set of expansion coefficients, $f_{l m}$, that minimise $J$ in Equation (14), we set

$$
\frac{\partial J}{\partial f_{l m}}=0
$$

for all appropriate values of $l$ and $m$. This constraint leads to a system of linear equations that can be written as

$$
\left(\mathbf{A}^{T} \mathbf{C}^{-1} \mathbf{A}+\lambda_{1} \mathbf{R}+\lambda_{2} \mathbf{I}\right) \mathbf{m}=\mathbf{A}^{T} \mathbf{C}^{-1} \mathbf{d}
$$

There is a unique solution if $\lambda_{1}>0$ or $\lambda_{2}>0 . \mathbf{m}$ is a vector containing the $M=(L+1)^{2}-1$ expansion coefficients where

$$
\mathbf{m}=\left(\begin{array}{c}
f_{1-1} \\
\vdots \\
f_{L L}
\end{array}\right)
$$

and $\mathbf{d}$ is an $N$-dimensional vector containing the data where

$$
\mathbf{d}=\left(\begin{array}{c}
d_{1} \\
\vdots \\
d_{N}
\end{array}\right)
$$

A is an $N \times M$ matrix given by

$$
\mathbf{A}=\left(\begin{array}{ccc}
\mathcal{Y}_{1-1}\left(\theta_{1}, \varphi_{1}\right) & \ldots & \mathcal{Y}_{L L}\left(\theta_{1}, \varphi_{1}\right) \\
\vdots & \ddots & \vdots \\
\mathcal{Y}_{1-1}\left(\theta_{N}, \varphi_{N}\right) & \cdots & \mathcal{Y}_{L L}\left(\theta_{N}, \varphi_{N}\right)
\end{array}\right)
$$

$\mathbf{C}=\operatorname{diag}\left(\sigma_{1}^{2}, \ldots, \sigma_{N}^{2}\right)$ is the covariance matrix and $\mathbf{I}$ is the identity matrix. $\mathbf{R}$ is an $M \times M$ matrix associated with gradient regularisation which is diagonal with components

$$
R_{l m l^{\prime} m^{\prime}}=l(l+1) \delta_{l l^{\prime}} \delta_{m m^{\prime}}
$$

where $\delta_{l l^{\prime}}$ is the Kronecker delta. 


\section{Data and Code Sources}

The oceanic residual depth measurements are tabulated in the Supplementary Information and available online. Seismic reflection surveys can be requested from ION. Isostatic and spherical harmonic inversion codes are available on request from

ftp://www.bullard.esc.cam.ac.uk/pub/incoming/mjh217.

\section{References}

[1] Pekeris, C. L. Thermal Convection in the Interior of the Earth. Geophysical Supplements to the Monthly Notices of the Royal Astronomical Society 3, 343-367 (1935).

[2] Turcotte, D. L. \& Schubert, G. Geodynamics (Cambridge University Press, Cambridge, 2002), 2nd edn.

[3] Richards, M. A. \& Hager, B. H. Geoid Anomalies in a Dynamic Earth. Journal of Geophysical Research 89, 5987-6002 (1984).

[4] Hager, B. H., Clayton, R. W. \& Richards, M. A. Lower mantle heterogeneity, dynamic topography and the geoid. Nature 313, 541-545 (1985).

[5] Schuberth, B. S. A. \& Bunge, H. P. Tomographic filtering of high-resolution mantle circulation models: Can seismic heterogeneity be explained by temperature alone? Geochemistry, Geophysics, Geosystems 10, 5 (2009).

[6] Davies, D. R. et al. Reconciling dynamic and seismic models of Earth's lower mantle: The dominant role of thermal heterogeneity. Earth and Planetary Science Letters 353354, 253-269 (2012).

[7] Steinberger, B. Effects of latent heat release at phase boundaries on flow in the Earths mantle, phase boundary topography and dynamic topography at the Earths surface. Physics of the Earth and Planetary Interiors 164, 2-20 (2007).

[8] Conrad, C. P. \& Husson, L. Influence of dynamic topography on sea level and its rate of change. Lithosphere 1, 110-120 (2009).

[9] Ricard, Y., Richards, M. A., Lithgow-Bertelloni, C. \& Le Stunff, Y. A Geodynamic Model of Mantle Density Heterogeneity. Journal of Geophysical Research 98, 21,895-21,909 (1993).

[10] Flament, N., Gurnis, M. \& Müller, R. D. A review of observations and models of dynamic topography. Lithosphere 5, 189-210 (2013).

[11] Moucha, R. et al. Dynamic topography and long-term sea-level variations: There is no such thing as a stable continental platform. Earth and Planetary Science Letters 271, 101-108 (2008).

[12] Bunge, H. P., Hagelberg, C. R. \& Travis, B. J. Mantle circulation models with variational data assimilation: Inferring past mantle flow and structure from plate motion histories and seismic tomography. Geophysical Journal International 152, 280-301 (2003). 
[13] Spasojević, S. \& Gurnis, M. Sea level and vertical motion of continents from dynamic earth models since the Late Cretaceous. AAPG Bulletin 96, 2037-2064 (2012).

[14] Crosby, A. G., McKenzie, D. P. \& Sclater, J. G. The relationship between depth, age and gravity in the oceans. Geophysical Journal International 166, 553-573 (2006).

[15] Menard, H. W. Depth Anomalies and the Bobbing Motion of Drifting Islands. Journal of Geophysical Research 78, 5128-5137 (1973).

[16] McKenzie, D. P. The influence of dynamically supported topography on estimates of Te. Earth and Planetary Science Letters 295, 127-138 (2010).

[17] Müller, R. D., Sdrolias, M., Gaina, C. \& Roest, W. R. Age, spreading rates, and spreading asymmetry of the world's ocean crust. Geochemistry, Geophysics, Geosystems 9, 4 (2008).

[18] White, R. S., McKenzie, D. P. \& O’Nions, R. K. Oceanic Crustal Thickness From Seismic Measurements and Rare Earth Element Inversions. Journal of Geophysical Research 97, $19,683-19,715$ (1992).

[19] Winterbourne, J. R., Crosby, A. G. \& White, N. J. Depth, age and dynamic topography of oceanic lithosphere beneath heavily sedimented Atlantic margins. Earth and Planetary Science Letters 287, 137-151 (2009).

[20] Czarnota, K., Hoggard, M. J., White, N. J. \& Winterbourne, J. Spatial and temporal patterns of Cenozoic dynamic topography around Australia. Geochemistry, Geophysics, Geosystems 14, 634-658 (2013).

[21] Winterbourne, J. R., White, N. J. \& Crosby, A. G. Accurate measurements of residual topography from the oceanic realm. Tectonics 33, 1-34 (2014).

[22] Crosby, A. G. \& McKenzie, D. P. An analysis of young ocean depth, gravity and global residual topography. Geophysical Journal International 178, 1198-1219 (2009).

[23] Hohertz, W. L. \& Carlson, R. L. An independent test of thermal subsidence and asthenosphere flow beneath the Argentine Basin. Earth and Planetary Science Letters 161, 73-83 (1998).

[24] Jackson, M. P. A., Hudec, M. R. \& Hegarty, K. A. The great West African Tertiary coastal uplift: Fact or fiction? A perspective from the Angolan divergent margin. Tectonics 24, TC6014 (2005).

[25] Guiraud, M., Buta-Neto, A. \& Quesne, D. Segmentation and differential post-rift uplift at the Angola margin as recorded by the transform-rifted Benguela and oblique-toorthogonal-rifted Kwanza basins. Marine and Petroleum Geology 27, 1040-1068 (2010).

[26] Roberts, G. G. \& White, N. J. Estimating uplift rate histories from river profiles using African examples. Journal of Geophysical Research 115, B02406 (2010).

[27] Smith, W. H. F. \& Sandwell, D. T. Global Sea Floor Topography from Satellite Altimetry and Ship Depth Soundings. Science 277, 1956-1962 (1997).

[28] Divins, D. L. Total Sediment Thickness of the World's Oceans \& Marginal Seas, NOAA National Geophysical Data Center, Boulder, CO (2003). 
[29] Laske, G. \& Masters, G. A Global Digital Map of Sediment Thickness, EOS Trans. AGU, 78, F483 (1997).

[30] Jordan, T. H. The Continental Tectosphere. Reviews of Geophysics 13, 1-12 (1975).

[31] Tapley, B. et al. The GGM03 Mean Earth Gravity Model from GRACE; Eos Trans. AGU 88(52), Fall Meet. Suppl., Abstract G42A-03 (2007).

[32] Colli, L., Ghelichkhan, S. \& Bunge, H.-P. On the ratio of dynamic topography and gravity anomalies in a dynamic Earth. Geophysical Research Letters 43 (2016).

[33] Wilson, J. W. P., Roberts, G. G., Hoggard, M. J. \& White, N. J. Cenozoic epeirogeny of the Arabian Peninsula from drainage modeling. Geochemistry, Geophysics, Geosystems 15, 3723-3761 (2014).

[34] Stephenson, S. N., Roberts, G. G., Hoggard, M. J. \& Whittaker, A. C. A Cenozoic uplift history of Mexico and its surroundings from longitudinal river profiles. Geochemistry, Geophysics, Geosystems 15, 4734-4758 (2014).

[35] Czarnota, K., Roberts, G. G., White, N. J. \& Fishwick, S. Spatial and temporal patterns of Australian dynamic topography from river profile modeling. Journal of Geophysical Research: Solid Earth 119, 1384-1424 (2014).

[36] Priestley, K. \& McKenzie, D. P. The relationship between shear wave velocity, temperature, attenuation and viscosity in the shallow part of the mantle. Earth and Planetary Science Letters 381, 78-91 (2013).

[37] Hager, B. H. \& Richards, M. A. Long-Wavelength Variations in Earth's Geoid: Physical Models and Dynamical Implications. Philosophical Transactions of the Royal Society A: Mathematical, Physical and Engineering Sciences 328, 309-327 (1989).

[38] Steinberger, B., Werner, S. C. \& Torsvik, T. H. Deep versus shallow origin of gravity anomalies, topography and volcanism on Earth, Venus and Mars. Icarus 207, 564-577 (2010).

[39] Forte, A. M. Constraints on Seismic Models from Other Disciplines - Implications for Mantle Dynamics and Composition. Treatise on Geophysics 805-858 (2007).

[40] Ritsema, J., Deuss, A., van Heijst, H. J. \& Woodhouse, J. H. S40RTS: a degree-40 shearvelocity model for the mantle from new Rayleigh wave dispersion, teleseismic traveltime and normal-mode splitting function measurements. Geophysical Journal International 184, 1223-1236 (2011).

[41] Cazenave, A., Souriau, A. \& Dominh, K. Global coupling of Earth surface topography with hotspots, geoid and mantle heterogeneities. Nature 340, 54-57 (1989).

[42] Wen, L. \& Anderson, D. L. Layered mantle convection: A model for geoid and topography. Earth and Planetary Science Letters 146, 367-377 (1997).

[43] Delorey, A. A., Dunn, R. A. \& Gaherty, J. B. Surface wave tomography of the upper mantle beneath the Reykjanes Ridge with implications for ridgehot spot interaction. Journal of Geophysical Research 112, B08313 (2007). 
[44] Rickers, F., Fichtner, A. \& Trampert, J. The Iceland-Jan Mayen plume system and its impact on mantle dynamics in the North Atlantic region: Evidence from full-waveform inversion. Earth and Planetary Science Letters 367, 39-51 (2013).

[45] Yale, M. M. \& Morgan, J. P. Asthenosphere flow model of hotspot-ridge interactions: A comparison of Iceland and Kerguelen. Earth and Planetary Science Letters 161, 45-56 (1998).

[46] Hartley, R. A., Roberts, G. G., White, N. \& Richardson, C. Transient convective uplift of an ancient buried landscape. Nature Geoscience 4, 562-565 (2011).

[47] Fichtner, A., Kennett, B. L. N., Igel, H. \& Bunge, H.-P. Full seismic waveform tomography for upper-mantle structure in the Australasian region using adjoint methods. Geophysical Journal International 179, 1703-1725 (2009).

[48] French, S., Lekic, V. \& Romanowicz, B. Waveform Tomography Reveals Channeled Flow at the Base of the Oceanic Asthenosphere. Science 342, 227-231 (2013).

[49] Dalton, C. A., Langmuir, C. H. \& Gale, A. Geophysical and Geochemical Evidence for Deep Temperature Variations Beneath Mid-Ocean Ridges. Science 344, 80-83 (2014).

[50] Buck, W. R., Small, C. \& Ryan, W. B. F. Constraints on asthenospheric flow from the depths of oceanic spreading centers: The East Pacific Rise and the Australian-Antarctic discordance. Geochemistry, Geophysics, Geosystems 10 (2009).

[51] Weismüller, J. et al. Fast asthenosphere motion in high-resolution global mantle flow models. Geophysical Research Letters 42, 7,429-7,435 (2015).

[52] Parsons, B. \& Sclater, J. G. An analysis of the variation of ocean floor bathymetry and heat flow with age. Journal of Geophysical Research 82, 803-827 (1977).

[53] Stein, C. \& Stein, S. A model for the global variation in oceanic depth and heat flow with lithospheric age. Nature 359, 123-139 (1992).

[54] Laske, G., Masters, G., Ma, Z. \& Pasyanos, M. Update on CRUST1.0 - A 1-degree Global Model of Earth's Crust. Geophysical Research Abstracts, 15, Abstract EGU2013-2658 (2013).

[55] Lago, B. \& Rabinowicz, M. Admittance for a convection in a layered spherical shell. Geophysical Journal of the Royal Astonomical Society 77, 461-482 (1984).

[56] Revenaugh, J. \& Parsons, B. Dynamic topography and gravity anomalies for fluid layers whose viscosity varies exponentially with depth. Geophysical Journal International 90, 349-368 (1987).

[57] Molnar, P., England, P. C. \& Jones, C. H. Mantle dynamics, isostasy, and the support of high terrain. Journal of Geophysical Research: Solid Earth 120, 1,932-1,957 (2015).

[58] Lambeck, K. Aristoteles : An ESA Mission to Study the Earth's Gravity Field. ESA Journal 14, 14 (1990).

[59] Kaula, W. M. Theorey of Satellite Geodesy (Blaisdell Publishing Company, Waltham, Massachusetts, 1966). 
[60] Courtillot, V., Davaille, A., Besse, J. \& Stock, J. Three distinct types of hotspots in the Earths mantle. Earth and Planetary Science Letters 205, 295-308 (2003).

[61] Bevier, M. L., Armstrong, R. L. \& Souther, J. G. Miocene peralkaline volcanism in westcentral British Columbia - Its temporal and place-tectonics setting. Geology 7, 389-392 (1979).

[62] Innocenti, F. et al. Neogene and Quaternary volcanism in Western Anatolia: Magma sources and geodynamic evolution. Marine Geology 221, 397-421 (2005).

[63] Bardintzeff, J. M., Liégeois, J. P., Bonin, B., Bellon, H. \& Rasamimanana, G. Madagascar volcanic provinces linked to the Gondwana break-up: Geochemical and isotopic evidences for contrasting mantle sources. Gondwana Research 18, 295-314 (2010).

[64] Whitehead, P. W. et al. Temporal development of the Atherton Basalt Province, north Queensland. Australian Journal of Earth Sciences 54, 691-709 (2007).

[65] Knesel, K. M., Souza, Z. S., Vasconcelos, P. M., Cohen, B. E. \& Silveira, F. V. Young volcanism in the Borborema Province, NE Brazil, shows no evidence for a trace of the Fernando de Noronha plume on the continent. Earth and Planetary Science Letters 302, 38-50 (2011).

[66] Vasconcelos, P. M., Knesel, K. M., Cohen, B. E. \& Heim, J. A. Geochronology of the Australian Cenozoic: a history of tectonic and igneous activity, weathering, erosion, and sedimentation. Australian Journal of Earth Sciences 55, 865-914 (2008).

[67] Maund, J. G., Rex, D. C., Le Roex, a. P. \& Reid, D. L. Volcanism on Gough Island: a revised stratigraphy. Geological Magazine 125, 175-181 (1988).

[68] Barling, J., Goldstein, S. L. \& Nicholls, I. A. Geochemistry of Heard Island (Southern Indian Ocean): Characterization of an enriched mantle component and implications for enrichment of the sub-Indian ocean mantle. Journal of Petrology 35, 1017-1053 (1994).

[69] Cucciniello, C. et al. New 40Ar-39Ar ages and petrogenesis of the Massif d'Ambre volcano, northern Madagascar. Geological Society of America Special Papers 478, 257-281 (2011).

[70] Camp, V. E. \& Roobol, M. J. Upwelling asthenosphere beneath western Arabia and its regional implications. Journal of Geophysical Research 97, 15,255-15,271 (1992).

[71] Macpherson, C. G. et al. Plio-Pleistocene intra-plate magmatism from the southern Sulu Arc, Semporna peninsula, Sabah, Borneo: Implications for high-Nb basalt in subduction zones. Journal of Volcanology and Geothermal Research 190, 25-38 (2010).

[72] Ferrari, L., Valencia-Moreno, M. \& Bryan, S. Magmatism and tectonics of the Sierra Madre Occidental and its relation with the evolution of the western margin of North America. Geological Society of America Special Paper 422 (2007).

[73] Johnson, K. T. M. et al. Boomerang Seamount: The active expression of the AmsterdamSt. Paul hotspot, Southeast India Ridge. Earth and Planetary Science Letters 183, 245-259 (2000). 
[74] Irving, A. J. \& Green, D. H. Geochemistry and petrogenesis of the newer basalts of Victoria and South Australia. Journal of the Geological Society of Australia 23, 45-66 (1976).

\section{Correspondence}

Correspondence and requests for materials should be addressed to M.J. Hoggard and N. White.

\section{Acknowledgements}

This research was supported by a BP-Cambridge collaboration. We are grateful to ION for permission to publish partial seismic reflection profiles shown in Figure 2 from their IndiaSPAN ${ }^{\mathrm{TM}}$ and Greater BrasilSPAN ${ }^{T M}$ datasets. We thank J. Austermann, P. Bellingham, J. Braun, R. Buck, A. Bump, H-P. Bunge, R. Corfield, A. Crosby, K. Czarnota, M. Falder, A. Forte, I. Frame, S. Ghelichkhan, D. Glassey, T. Heyn, B. Horn, S. Kisin, D. Lyness, L. Mackay, K. McDermott, D. McKenzie, R. Parnell-Turner, F. Richards, G. Roberts, B. Schuberth, B. Steinberger, E. Stirling, M. Thompson, J. Weismüller, J. Wilson and J. Winterbourne for their help. Figures were prepared using Generic Mapping Tools and routines from the SHTOOLS package were used in the spherical harmonic analysis. Earth Sciences contribution esc.3605.

\section{Author Contributions}

This project was conceived and managed by NW. MJH processed, interpreted and modelled the databases with guidance from NW and DA-A. The paper was written by all three authors.

\section{Additional Information}

Data and synthetic tests reported in this paper are tabulated in the Supplementary Information.

\section{Competing Financial Interests}

The authors declare no competing financial interests. 


\section{Supplementary Information}

\section{Exclusion Polygons}

A sufficiently accurate grid of crustal thickness throughout the oceanic realm is not yet available. As a result, residual topographic estimates determined from ship-track observations are not isostatically corrected for anomalous crustal thickness. This shortcoming means that it is essential to manually and conservatively excise all regions where anomalously thick or thin oceanic crust occurs, using high resolution bathymetric and gravity anomaly maps. The resultant exclusion polygons are shown in Figure 7a.

On the continents, we have estimated dynamic topography by scaling long-wavelength freeair gravity anomalies using a constant admittance of $+50 \mathrm{mGal} \mathrm{km}^{-1}$. It is important to excise all regions where gravity anomalies are affected by active/ancient orogenic belts and by flexure at subduction zones. We used a combination of gravity, topographic and geological maps to manually excise these regions. The resultant exclusion polygons are shown in Figure $7 \mathrm{~b}$.
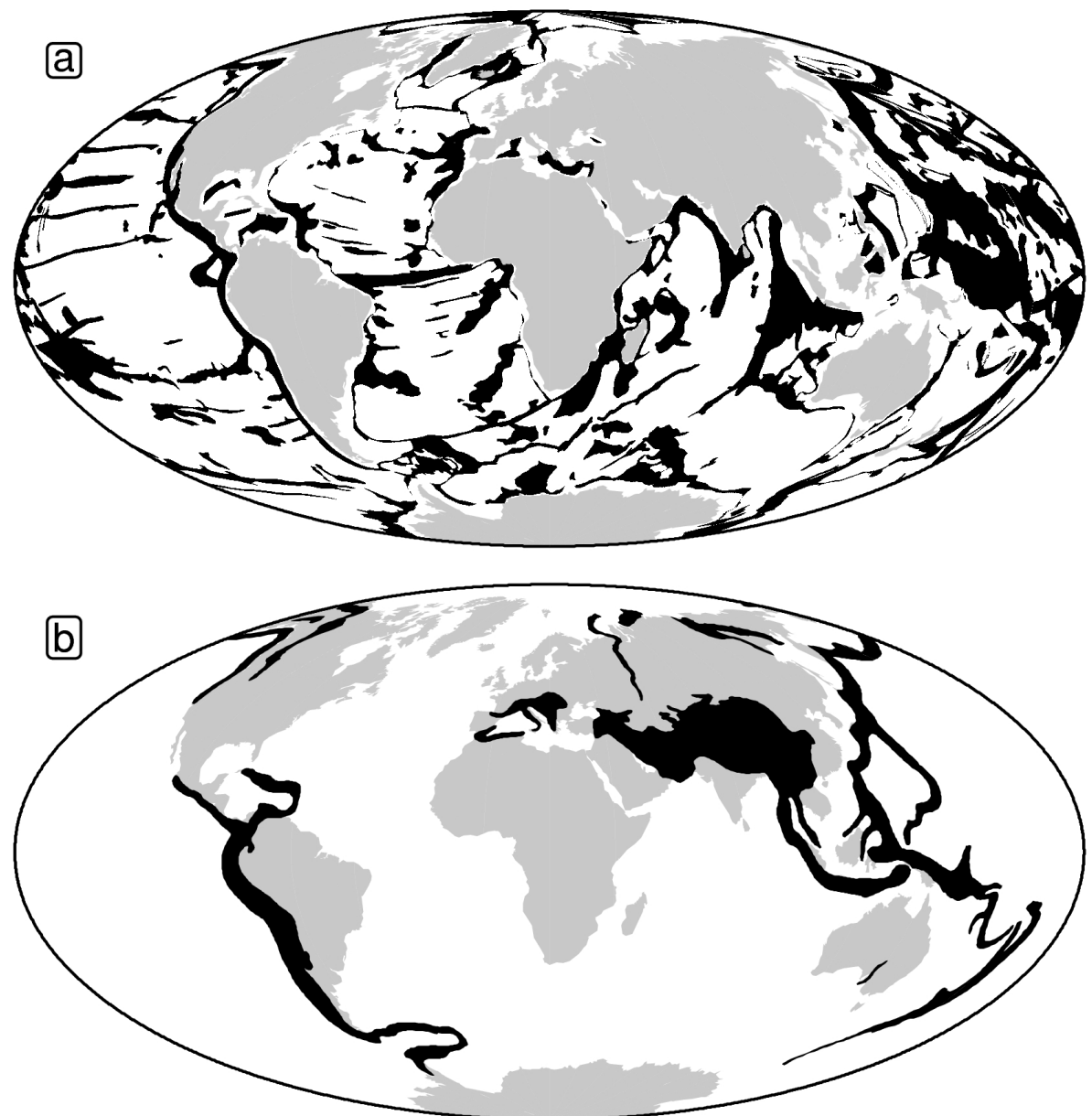

Figure 7: Exclusion polygons. (a) Distribution of exclusion polygons within oceanic realm that were used to excise regions of anomalously thick or thin oceanic crust from residual topographic measurements derived from ship-track database. (b) Distribution of exclusion polygons that were used to excise orogenic and flexural zones from maps of long-wavelength gravity anomalies. 


\section{Alternative Age-Depth Relationships}

To demonstrate the robustness of the power spectrum of observed dynamic topography shown in Figure 5b, we recalculated oceanic residual topography from spot measurements and ship-track observations using alternative age-depth relationships (Figure 8a). First, we calculated residual topography using the well-known plate cooling models of Parsons and Sclater ${ }^{52}$ and Stein and Stein $^{53}$. Secondly, we fitted a new plate cooling model by minimising the misfit between this model and spot measurements from the oceanic realm. Thirdly, we fitted a half-space (i.e. $\sqrt{t}$ ) cooling model using the same approach. Finally, we fitted a different half-space cooling model to only observations from oceanic floor younger than $70 \mathrm{Ma}$. We then extrapolated this relationship to older ages. This extreme approach implies that seafloor flattening could conceivably make a significant contribution to long-wavelength dynamic topography. However, all calculated power spectra are in close agreement with our previous results (Figure 8b).


Figure 8: Alternative age-depth relationships. (a) Solid points $=2,120$ measurements of water-loaded depth to oceanic basement as function of plate age; solid/dashed lines $=$ age-depth relationships ${ }^{22,52,53}$; dotted lines = calculated plate and half-space cooling models. (b) Power spectra of observed dynamic topography using four different age-depth relationships. Grey line/bounds = mean/standard deviation of the five predictive dynamic topography models. 


\section{Continental Dynamic Topography}

We have carried out a series of tests which check how different methods for calculating dynamic topography on the continents affect our observed power spectrum shown in Figure 5b. In the first pair of tests, we have completely excised the continents and calculated power spectra using oceanic observations alone. One of these tests includes all oceanic observations (i.e. spot measurements and edited ship-track data) and the other test includes only the most reliable oceanic observations (i.e. 2,120 spot measurements alone). Calculated power spectra are in close agreement (Figure 9a). Thus excision of gravity-derived continental estimates and oceanic ship-track data does not significantly alter our substantive result concerning the discrepancies between observed and predicted spectra.

In a second set of tests, we calculated continental dynamic topography using the CRUST1.0 digital grid of Laske et al. ${ }^{54}$. Their grid was first re-sampled at continental nodes that are identical to those shown in Figure 1b. Dynamic topography was calculated at each node using an isostatic balance between the thickness and density structure of crust taken from CRUST1.0 and the structure of an unperturbed mid-oceanic ridge. The related issue of lithospheric thickness and density was addressed in three different ways. First, we assumed that continental lithosphere had a constant thickness everywhere of $125 \mathrm{~km}$. Secondly, we assumed that lithospheric thickness varied in accordance with the surface wave tomographic model estimates of Priestley and McKenzie ${ }^{36}$. Thirdly, we incorporated the effects of chemical depletion (i.e. the existence of harzburgitic lithospheric mantle in cratonic regions) by reducing the average density of lithospheric mantle that is thicker than $175 \mathrm{~km}$ by 10 and $30 \mathrm{~kg} \mathrm{~m}^{-3}$.

The four resultant power spectra are shown in Figure 9b. Our series of tests show that spectral power at $l=2$ remains an order of magnitude smaller than that of predictive models. Similarly, spectral power at $l=20-30$ remains significant. In each case, spectral slopes match that obtained using long-wavelength free-air gravity anomalies. There is greater spectral power at all degrees since the amplitude of continental dynamic topography predicted by CRUST 1.0 is much greater than that observed within the oceanic realm. For example, the test which uses constant lithospheric thickness has air-loaded dynamic topographic peaks of $\pm 3.5 \mathrm{~km}$. Given observed peak water-loaded oceanic residual depth anomalies are $\pm 2.5 \mathrm{~km}$, we might expect equivalent air-loaded values of only $\pm 1.7 \mathrm{~km}$. Inclusion of variable lithospheric thickness reduces both amplitude and spectral power of continental dynamic topography. However, if significant depletion is permitted within thicker cratonic regions, the buoyancy contribution of thick lithosphere is essentially cancelled out due to the isopycnal effect.

There are two significant drawbacks in exploiting CRUST1.0. First, a feature of this (and other) digital databases is that the original raw input data is not provided, which means that the fidelity of the CRUST1.0 database cannot be verified or assessed. It is constructed from a variety of data sources whose resolution and accuracy is variable. It is also extrapolated away from actual measurements into regions where data coverage is either poor or non-existent. Secondly, the amplitude of dynamic topography from CRUST 1.0 on its own is geologically implausible. It is essential to include the buoyancy effects associated with variable lithospheric thickness - a correction that is clearly of paramount importance in the oceanic realm. We prefer the use of long-wavelength free-air gravity anomalies to estimate continental dynamic topography. In the oceanic realm, these anomalies correlate surprisingly well with residual depth estimates (e.g. Figure 3 of main text). There is also a good match at passive margins where oceanic lithosphere abuts the continents.

Finally, we investigate the spectral consequences of changing the value of admittance, $Z=50 \mathrm{mGal} \mathrm{km}^{-1}$, used to estimate continental dynamic topography from long-wavelength 




Figure 9: Continental Tests. (a) Power spectra for decimated datasets. Solid line $=$ power spectrum for complete observational database (Figure $1 \mathrm{~b}$ of main text); dashed line $=$ power spectrum for oceanic spot measurements and ship-track data alone (i.e. no continental input); dotted line $=$ power spectrum for oceanic spot measurements alone. Grey line/band $=$ mean/standard deviation of 5 predictive models of dynamic topography ${ }^{7,8,9,10,13}$. (b) Power spectra for alternative continental observations. Black line = power spectrum using continental dynamic topography calculated from long-wavelength free-air gravity anomalies; yellow line = power spectrum using continental dynamic topography calculated from CRUST 1.0 database assuming constant lithospheric thickness of $125 \mathrm{~km}^{54}$; red line $=$ as before but using variable lithospheric thickness ${ }^{36}$; blue line $=$ as before where lithosphere thicker than $175 \mathrm{~km}$ is depleted by $10 \mathrm{~kg} \mathrm{~m}^{-3}$; green line $=$ as before with depletion of $30 \mathrm{~kg} \mathrm{~m}^{-3}$. (c) Coloured lines = power spectra using continental dynamic topography calculated from long-wavelength free-air gravity anomalies using admittance values ranging from $25-100 \mathrm{mGal} \mathrm{km}^{-1}$. 
free-air gravity anomalies. In Figure 9c, a range of $Z=25-100 \mathrm{mGal} \mathrm{km}^{-1}$ has been used. The resultant power spectra have similar slopes. When $Z$ increases, spectral power for continental dynamic topography decreases for all wavelengths. As $Z \rightarrow \infty$, continental dynamic topography tends toward zero and the resultant power spectrum is dominated by oceanic measurements. As $Z \rightarrow 0$, continental dynamic topography becomes unrealistically large. Thus admittance of less than $Z=25 \mathrm{mGal} \mathrm{km}^{-1}$ is unlikely since it gives rise to geologically implausible values. For example, $Z=10 \mathrm{mGal} \mathrm{km}^{-1}$ yields peak dynamic topographic amplitudes of $\pm 8 \mathrm{~km}$.

Several studies have suggested that admittance can vary as a function of wavelength e.g. ${ }^{32,55,56,57}$. For example, Revenaugh and Parsons ${ }^{56}$ argue that $Z$ varies from 25 to $75 \mathrm{mGal} \mathrm{km}^{-1}$ for wavelengths of $2 \times 10^{4}$ and $2 \times 10^{3} \mathrm{~km}$, if mantle viscosity decreases exponentially with depth. We have tested the spectral implications of this proposed variation by assuming that

$$
Z(l)=50 \tanh \left(\frac{l}{a}\right)
$$

where $Z(l)$ is admittance as a function of degree and $a$ is a constant term that controls how quickly admittance reaches $50 \mathrm{mGal} \mathrm{km}^{-1}$. The consequences of using three different admittance curves where $a=2,5$ and 10 are investigated (Figure 10a). Significantly, the resultant harmonic representations of dynamic topography do not accurately match our oceanic residual depth observations. As before, these global grids have been used to constrain continental dynamic topography by re-sampling the grids at identical onshore nodes. Power spectra were then calculated. Even for the extreme case of $a=10$ that implies $Z \approx 10 \mathrm{mGal} \mathrm{km}^{-1}$ at $l=2$, there is a one order of magnitude difference between observed and predicted power for $l=2$ (Figure 10c). We confidently conclude that our choice of continental admittance is not the source of spectral discrepancies between observed and predicted dynamic topography. 

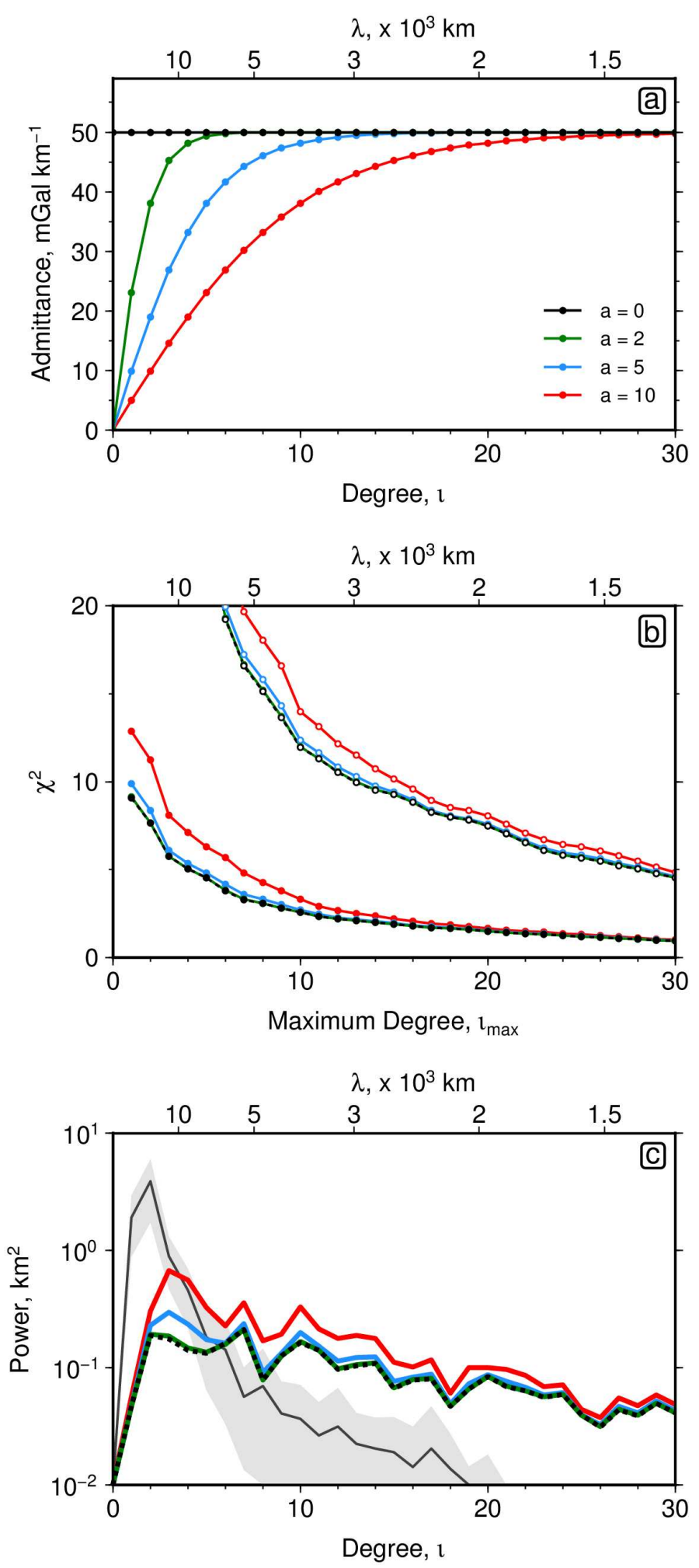

Figure 10: Wavelength-dependent admittance tests. (a) Admittance curves used to calculate four different sets of gravity-derived continental dynamic topographic databases. (b) Residual misfit, $\chi^{2}$, for these four sets. Solid circles = oceanic and continental databases; open circles = spot measurements from oceanic realm alone. (c) Power spectra. Thick lines = power spectra calculated from four different sets of databases; thin line with grey bounds $=$ mean and standard deviation of power spectra for five predictive models. 


\section{Checkerboard, Damping and Benchmarking Tests}

We have carried out a series of tests which enable us to assess how different data coverage affects the recoverability of our spherical harmonic analysis. First, a series of checkerboard tests were performed. Three different input models were constructed: (i) $l=10$ and $m=5$; (ii) $l=20$ and $m=10$; and (iii) $l=30$ and $m=15$ (Figures 11a, 12a and 13a). Each input model was sub-sampled in accordance with the distribution of measurements from oceanic and continental realms (Figures 11b, 12b and 13b). Regularised least squares inversion of each subsampled distribution demonstrates the fidelity of signal recovery (Figures 13c, 13c and 13c). If the continental realm is completely removed, signal recovery of the oceanic realm is good (Figures 11e, 12e and 13e). Finally, if only spot measurements from the oceanic realm are included, signal recovery is still satisfactory (Figures $11 \mathrm{~g}, 12 \mathrm{~g}$ and $13 \mathrm{~g}$ ).

Secondly, we explored the effects of gradient smoothing, $\lambda_{1}$, and amplitude damping, $\lambda_{2}$, upon the recoverability of power spectra. $\lambda_{1}$ and $\lambda_{2}$ were systematically varied between $10^{-0.5}$ $10^{+0.5}$ and $10^{2}-10^{3}$, respectively. When both are zero, the recovered power spectrum becomes convex upward between $l=10$ and $l=20$. When any regularisation is introduced, resultant spectra stabilise and exhibit little significant variation apart from a gradual decrease in overall amplitudes. This range of regularisation parameters gives rise to the calculated error bounds shown in Figure $5 b$ of the main text.

Thirdly, we benchmarked our ability to recover red spectra by analysing the predictive model of Flament et al. ${ }^{10}$. We sub-sampled this model in accordance with the distribution of our oceanic and continental observations. Random noise was added, scaled by the uncertainty associated with each observation. We then carried out a regularised least squares inversion of a series of increasingly decimated data distributions. Recovered power spectra closely resemble the original spectrum of the predictive model (Figure 14). 



Figure 11: Synthetic checkerboard test. (a) Input spherical harmonic function with $l=10$ and $m=5$. (b) Locations of all oceanic and continental data points used to sub-sample input model. (c) Resulting spherical harmonic fit with recovery of input coefficients. (d) All measurements from oceanic realm alone. (e) Recovery obtained using (d). (f) Only spot measurements from oceanic realm (symbols from Figure $1 \mathrm{~b}$ of main text). (g) Recovery obtained using (f). 

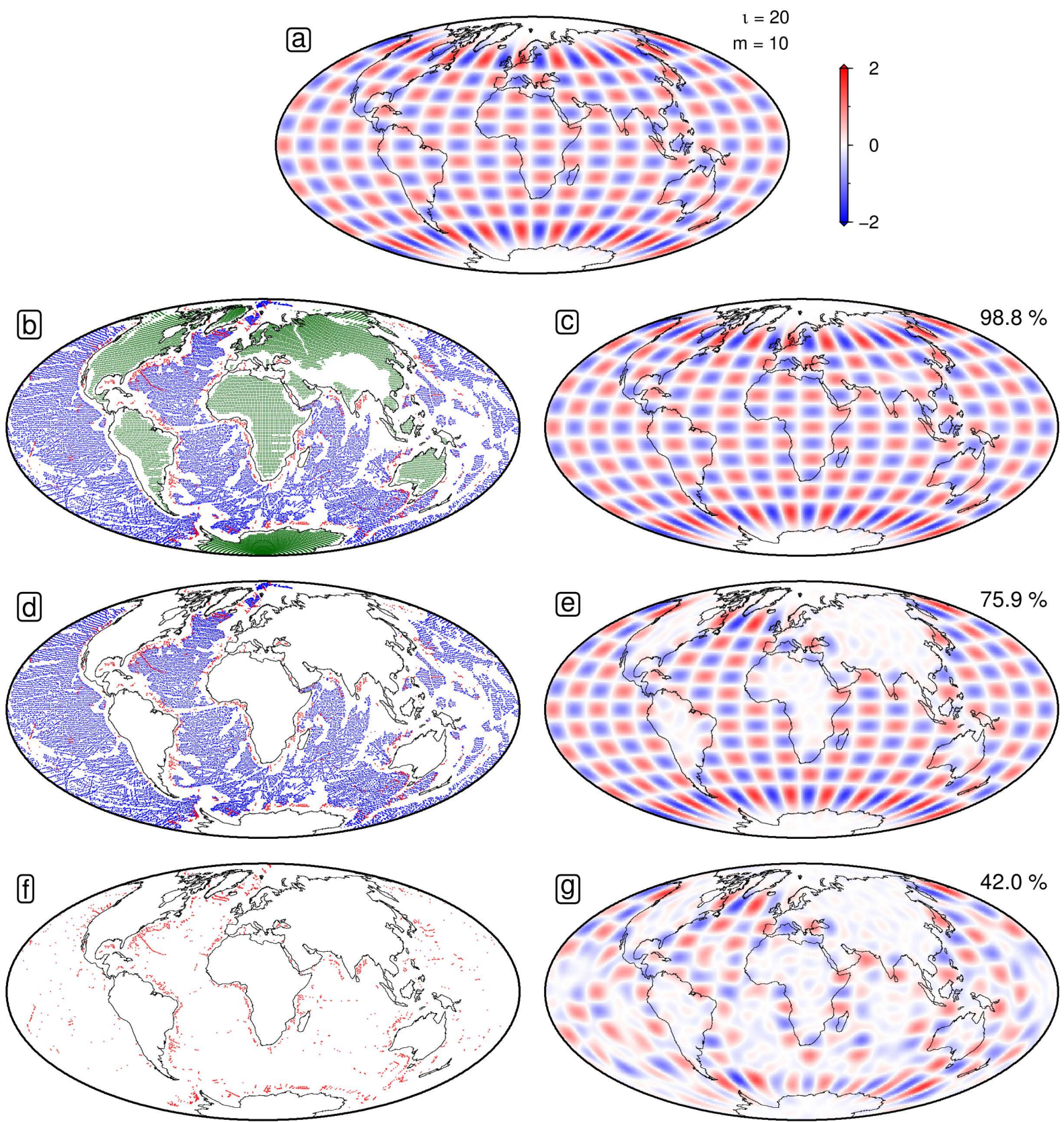

Figure 12: Synthetic checkerboard test. (a) Input spherical harmonic function with $l=20$ and $m=$ 10. (b) Locations of all oceanic and continental data points used to sub-sample input model. (c) Resulting spherical harmonic fit with recovery of input coefficients. (d) All measurements from oceanic realm alone. (e) Recovery obtained using (d). (f) Only spot measurements from oceanic realm (symbols from Figure $1 \mathrm{~b}$ of main text). (g) Recovery obtained using (f). 

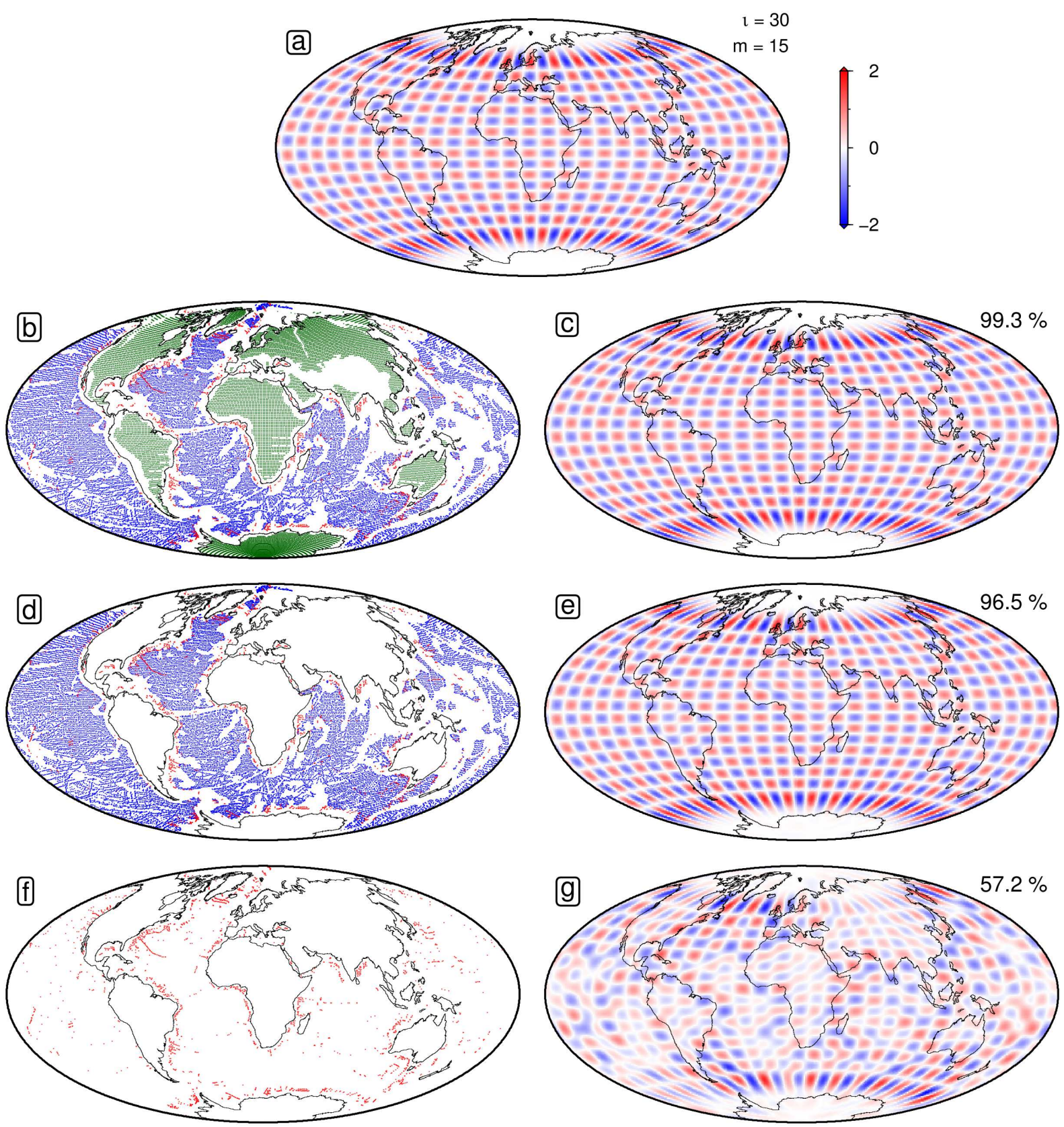

Figure 13: Synthetic checkerboard test. (a) Input spherical harmonic function with $l=30$ and $m=$ 15. (b) Locations of all oceanic and continental data points used to sub-sample input model. (c) Resulting spherical harmonic fit with recovery of input coefficients. (d) All measurements from oceanic realm alone. (e) Recovery obtained using (d). (f) Only spot measurements from oceanic realm (symbols from Figure $1 \mathrm{~b}$ of main text). (g) Recovery obtained using (f). 



Figure 14: Benchmark test. (a) Solid line = power of predicted dynamic topographic model shown in (b); dashed line $=$ recovered power using data distribution shown in (c); dotted line $=$ recovered power using data distribution shown in (e). (b) Global dynamic topography prediction from Flament et al. ${ }^{10}$. (c) Oceanic and continental data points used to sub-sample input model. (d) Recovered model obtained using (c). (e) Oceanic data points. (f) Recovered model obtained using (e). 


\section{Latitudinal Test}

Residual depth observations are averaged into $1^{\circ}$ bins which results in an increased density of data toward higher latitudes. To check whether this density increase affects our results, we have carried out an inversion for which each datapoint is weighted by the surface area of the $1^{\circ}$ bin within which it lies. The modified misfit function is

$$
\chi^{2}=\frac{1}{N} \sum_{i=1}^{N} \frac{1}{\sigma_{i}^{2}}\left(\frac{A_{i}}{A_{45}}\right)\left[f\left(\theta_{i}, \varphi_{i}\right)-d_{i}\right]^{2}
$$

where $A_{i}$ is the area of a $1^{\circ}$ bin and $A_{45}$ is the area of a $1^{\circ}$ bin at a latitude of $45^{\circ}$. In this way, points closer to either pole are correctly weighted with respect to points which are closer to the equator. The resultant power spectrum is very similar to that calculated without latitudinal weighting, which means that this effect does not alter our conclusions (Figure 15). 



Figure 15: Effect of weighting the data by latitude. (a) Residual misfit, $\chi^{2}$, plotted as function of maximum degree; solid circles $=\chi^{2}$ values from fitting combined offshore/onshore global database of dynamic topographic observations; open circles $=\chi^{2}$ values from fitting spot measurements from oceanic realm alone; black = original, non-latitude weighted data; red = including a latitude weighting. (b) Power spectra of observed dynamic topography using non-latitude (black) and latitude-weighted (red) misfit functions. Grey line/bounds = mean/standard deviation of the five predictive models. 


\section{Kaula's Rule}

The Earth's gravity field can be described using spherical harmonic coefficients. Power, $P_{l}^{\Delta g}$, as a function of degree, $l$, is given by

$$
P_{l}^{\Delta g}=\left(\frac{G M}{R^{2}}\right)^{2}(l-1)^{2} \sum_{m=-l}^{l} f_{l m}^{2}
$$

where $G=6.67 \times 10^{-11} \mathrm{~m}^{3} \mathrm{~kg}^{-1} \mathrm{~s}^{-2}$ is the gravitational constant, $M=5.97 \times 10^{24} \mathrm{~kg}$ is the mass of the Earth, $R=6371 \mathrm{~km}$ is the radius of the Earth, and $f_{l m}$ are the fully normalised spherical harmonic coefficients ${ }^{58}$.

Kaula ${ }^{59}$ proposed a rule of thumb to estimate the order of magnitude of each coefficient as a function of degree, where $f_{l m}=10^{-5} / l^{2}$. Satellite observation was in its infancy and only the first few coefficients for the lowest degrees were known. Nevertheless, this rule has proven to be surprisingly accurate for spherical expansions of up to $l=360$ and higher. Combining Kaula's rule with Equation $(24)$ and noting that for each degree there are $(2 l+1)$ separate coefficients, the calculated power of dynamic topography is given by

$$
P_{l}^{D T}=\left(\frac{G M}{Z R^{2}}\right)^{2}\left(\frac{2}{l}-\frac{3}{l^{2}}+\frac{1}{l^{4}}\right)
$$

where $G=6.67 \times 10^{-11} \mathrm{~m}^{3} \mathrm{~kg}^{-1} \mathrm{~s}^{-2}$ is the gravitational constant, $M=5.97 \times 10^{24} \mathrm{~kg}$ is mass of the Earth, $R=6371 \mathrm{~km}$ is radius of the Earth, and $Z$ is the admittance. If $Z=12 \pm 3$

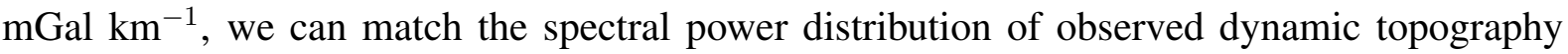
(Figure 16). Note that $Z$ is independent of degree.

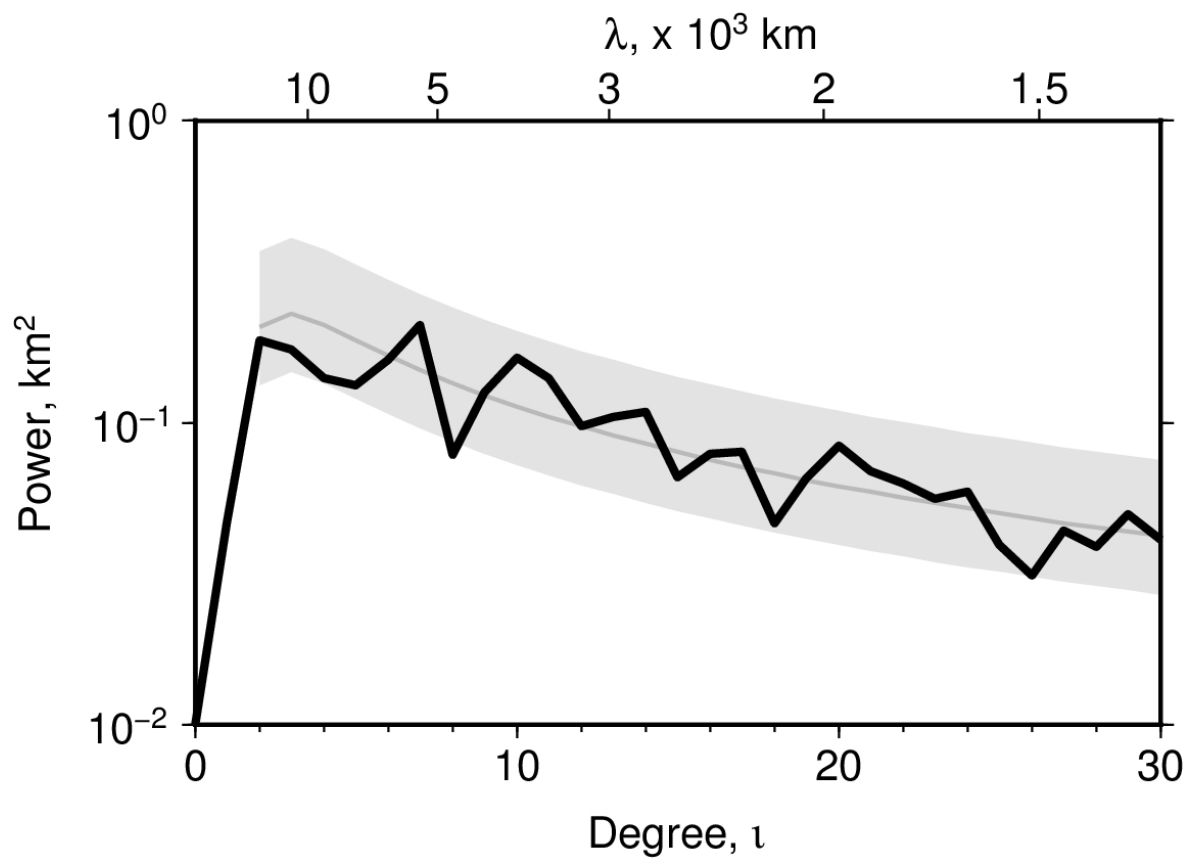

Figure 16: Kaula's rule. Solid line $=$ power spectrum of observational database (Figure $5 \mathrm{~b}$ in main text); grey line/band = power spectrum calculated using Equation 25 for $Z=12 \pm 3 \mathrm{mGal} \mathrm{km}^{-1}$. 


\section{Isostatic Vertical Displacement Caused by an Asthenospheric Channel}

The air-loaded vertical displacement generated by a sub-plate asthenospheric channel is calculated by balancing the lithostatic pressure at the base of two columns (Figure 17). This calculation assumes that the flow field has zero vertical component. The pressure beneath the original column, $P_{a}$, is given by

$$
P_{a}=\rho_{l} g z_{l}+\rho_{\circ}\left(1-\alpha T_{\circ}\right) g(h-U)
$$

where $g$ is gravitational acceleration, $\rho_{l}$ and $z_{l}$ are density and thickness of lithosphere respectively, and $\rho_{\circ}$ is asthenospheric density at $0^{\circ} \mathrm{C}$ (Figure 17a). $U$ is the air-loaded isostatic uplift, $h$ is the channel thickness, $\alpha$ is the thermal expansion coefficient and $T_{\circ}$ is the average temperature of the channel (Figure 17b). The pressure beneath the perturbed column, $P_{b}$, is given by

$$
P_{b}=\rho_{l} g z_{l}+\rho_{\circ}\left[1-\alpha\left(T_{\circ}+\Delta T\right)\right] g h
$$

where $\Delta T$ is the average excess temperature within the channel. If these two columns are in isostatic equilibrium, then $P_{a}=P_{b}$. Expanding Equations 26 and 27, cancelling out common factors, and re-arranging yields

$$
\Delta T=\frac{U\left(1-\alpha T_{\circ}\right)}{h \alpha} .
$$

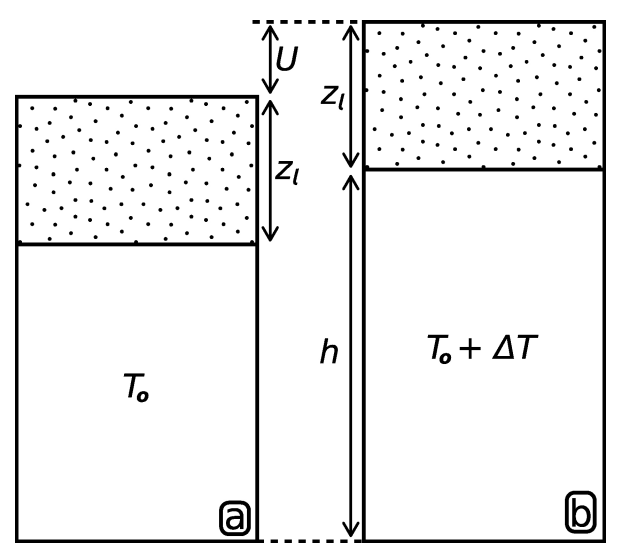

Figure 17: Sub-plate asthenospheric isostatic balance. (a) Standard case, where $T_{0}=$ average temperature of the asthenosphere. Dotted pattern $=$ crust and lithospheric mantle. (b) Air-loaded uplift, $U$, generated from a sub-plate channel of thickness $h$, and average temperature $T_{\circ}+\Delta T$. 


\section{Residual Depth Database}

Table 1: 1,006 accurate residual depth measurements (circles in Figure 1b of main text), averaged over $1^{\circ}$ bins.

\begin{tabular}{|c|c|c|c|c|c|c|}
\hline Lon. $^{a}$ & Lat. $^{a}$ & $z_{r}, \mathrm{~m}$ & Error, $\mathrm{m}$ & Lon. $^{a}$ & Lat. ${ }^{a}$ & $z_{r, \mathrm{~m}}$ \\
\hline 7.49 & 70.00 & 551 & 104 & 8.01 & 69.80 & 689 \\
\hline 10.97 & 69.68 & 495 & 103 & -15.83 & 69.87 & 1776 \\
\hline-13.00 & 69.56 & 1842 & 32 & -12.48 & 69.50 & 1899 \\
\hline 9.02 & 69.27 & 450 & 104 & 9.60 & 69.00 & 406 \\
\hline-64.54 & 69.47 & 1011 & 137 & -63.98 & 69.33 & 792 \\
\hline-61.12 & 68.59 & 619 & 170 & -15.66 & 69.46 & 1723 \\
\hline-10.43 & 69.38 & 1922 & 61 & 0.98 & 67.71 & 1315 \\
\hline-59.39 & 68.15 & 1416 & 189 & -18.12 & 67.82 & 1828 \\
\hline 1.07 & 65.91 & 1353 & 81 & 1.61 & 65.57 & 1292 \\
\hline-3.00 & 65.97 & 1038 & 100 & -2.05 & 65.65 & 1082 \\
\hline 2.10 & 65.26 & 1404 & 75 & -33.53 & 65.48 & 511 \\
\hline-31.34 & 64.57 & 1371 & 64 & -1.54 & 65.48 & 1250 \\
\hline-31.01 & 64.43 & 1146 & 66 & -23.61 & 63.55 & 2072 \\
\hline-37.26 & 62.58 & 1018 & 160 & -24.64 & 63.04 & 2107 \\
\hline-36.16 & 62.22 & 958 & 114 & -26.75 & 61.74 & 1654 \\
\hline-24.27 & 61.61 & 2013 & 46 & -57.22 & 60.79 & 762 \\
\hline 177.18 & 59.86 & -509 & 145 & -59.72 & 59.90 & 247 \\
\hline-56.88 & 59.52 & 301 & 130 & -51.79 & 59.88 & 805 \\
\hline-20.41 & 59.55 & 972 & 118 & 177.19 & 59.00 & -362 \\
\hline-57.22 & 59.34 & 524 & 126 & -42.66 & 59.10 & 418 \\
\hline-40.44 & 58.52 & 644 & 97 & -20.20 & 59.45 & 759 \\
\hline-176.97 & 57.62 & -488 & 167 & -55.97 & 57.77 & 328 \\
\hline-32.74 & 57.75 & 1257 & 7 & -32.23 & 57.61 & 1631 \\
\hline-54.99 & 57.07 & 845 & 115 & -54.19 & 56.97 & 1020 \\
\hline-23.30 & 56.92 & 1212 & 59 & -53.74 & 56.30 & 394 \\
\hline-163.59 & 52.54 & -425 & 28 & -163.53 & 52.45 & -220 \\
\hline-171.66 & 50.25 & 223 & 14 & -44.69 & 50.34 & 922 \\
\hline-14.72 & 48.60 & 364 & 56 & -14.04 & 48.79 & 247 \\
\hline-129.00 & 47.98 & 350 & 65 & -128.12 & 47.78 & 264 \\
\hline-130.85 & 47.31 & 577 & 60 & -129.91 & 47.06 & 485 \\
\hline-7.40 & 46.51 & -1158 & 146 & -127.95 & 46.39 & 114 \\
\hline-43.16 & 46.10 & 493 & 131 & -7.78 & 46.09 & -1108 \\
\hline-131.23 & 45.22 & 366 & 58 & -129.66 & 44.83 & 235 \\
\hline-126.16 & 44.64 & 112 & 81 & -46.67 & 44.58 & 307 \\
\hline-43.48 & 44.73 & 501 & 99 & -8.58 & 44.84 & -1263 \\
\hline-53.28 & 43.53 & -339 & 236 & -47.09 & 43.58 & -652 \\
\hline 32.16 & 43.06 & -2125 & 493 & 33.04 & 43.31 & -2885 \\
\hline 37.98 & 42.90 & -917 & 327 & 38.78 & 42.64 & -1066 \\
\hline-58.20 & 43.03 & -1519 & 274 & -53.37 & 43.45 & -531 \\
\hline 5.18 & 41.56 & -1078 & 227 & 37.99 & 42.35 & -181 \\
\hline 137.00 & 42.10 & -879 & 88 & 137.72 & 42.40 & -831 \\
\hline-60.34 & 41.85 & -1355 & 190 & -57.67 & 41.99 & -851 \\
\hline 5.36 & 41.41 & -1239 & 217 & 5.93 & 40.93 & -1554 \\
\hline-57.38 & 41.38 & -807 & 166 & -13.63 & 40.50 & -924 \\
\hline 147.94 & 40.00 & -308 & 72 & 150.82 & 40.05 & -164 \\
\hline 5.55 & 38.53 & -300 & 153 & 145.18 & 38.98 & 47 \\
\hline 148.13 & 39.09 & -338 & 64 & 148.63 & 39.02 & -379 \\
\hline 5.61 & 38.00 & -317 & 155 & 147.69 & 38.47 & -314 \\
\hline-11.16 & 38.12 & -1102 & 148 & 2.49 & 37.47 & -546 \\
\hline 153.25 & 36.69 & -548 & 68 & 153.91 & 36.74 & -620 \\
\hline-123.50 & 37.22 & -48 & 89 & -123.38 & 37.28 & -37 \\
\hline 145.16 & 36.27 & -336 & 63 & 146.01 & 36.10 & -358 \\
\hline-73.75 & 36.45 & -524 & 222 & -73.42 & 36.39 & -573 \\
\hline 146.55 & 35.39 & -503 & 64 & -72.69 & 34.75 & -790 \\
\hline-36.51 & 34.59 & 455 & 32 & -36.40 & 34.92 & 577 \\
\hline 146.49 & 34.33 & -470 & 64 & 147.07 & 34.06 & -429 \\
\hline 150.12 & 33.86 & -401 & 66 & 152.02 & 33.96 & -459 \\
\hline 154.56 & 34.02 & -278 & 65 & -73.15 & 34.00 & -963 \\
\hline-37.72 & 33.88 & 25 & 34 & -37.09 & 34.31 & 67 \\
\hline-10.36 & 34.31 & -1066 & 166 & 34.14 & 32.85 & -270 \\
\hline-73.45 & 33.42 & -1091 & 154 & -71.78 & 32.62 & -812 \\
\hline 33.86 & 32.11 & 216 & 334 & 34.56 & 32.43 & -88 \\
\hline-76.16 & 32.10 & -794 & 219 & -69.81 & 32.06 & -414 \\
\hline 143.98 & 31.07 & -365 & 61 & 144.77 & 31.00 & -425 \\
\hline 148.03 & 30.71 & -635 & 63 & 148.75 & 30.73 & -662 \\
\hline-68.00 & 31.18 & -216 & 77 & -67.03 & 30.69 & -210 \\
\hline-66.29 & 30.30 & -45 & 77 & -65.41 & 29.83 & 65 \\
\hline-63.19 & 28.61 & 36 & 60 & 147.12 & 27.59 & -256 \\
\hline-71.07 & 28.17 & -557 & 89 & -69.64 & 27.83 & -525 \\
\hline-62.08 & 27.97 & -229 & 59 & -61.45 & 27.61 & -569 \\
\hline 147.00 & 27.14 & -249 & 71 & 147.85 & 27.07 & -283 \\
\hline-110.36 & 26.60 & -412 & 122 & -89.76 & 26.91 & -1246 \\
\hline-87.05 & 26.69 & -696 & 262 & -60.74 & 27.19 & -648 \\
\hline-93.93 & 26.01 & -1713 & 383 & -93.15 & 25.92 & -1791 \\
\hline-89.95 & 25.98 & -1388 & 312 & -88.96 & 26.25 & -1200 \\
\hline-86.20 & 25.85 & -458 & 219 & -75.26 & 25.71 & 136 \\
\hline 146.14 & 25.18 & -575 & 75 & -86.67 & 25.40 & -560 \\
\hline-75.05 & 25.38 & 98 & 98 & -56.96 & 24.94 & -393 \\
\hline-54.42 & 24.28 & -605 & 67 & -53.35 & 24.00 & -625 \\
\hline-21.66 & 23.82 & -304 & 100 & -21.00 & 23.69 & -202 \\
\hline 65.70 & 22.76 & -4 & 284 & 121.92 & 22.83 & -769 \\
\hline-108.04 & 23.23 & -148 & 105 & -50.84 & 23.35 & -573 \\
\hline-19.71 & 23.45 & -286 & 139 & -18.94 & 23.21 & -353 \\
\hline 65.03 & 22.19 & 203 & 205 & -108.59 & 22.45 & -51 \\
\hline-67.84 & 22.27 & -494 & 79 & -67.25 & 22.25 & -656 \\
\hline 38.69 & 19.59 & 1497 & 67 & 60.37 & 20.13 & 614 \\
\hline 64.94 & 19.88 & 71 & 148 & 66.09 & 19.77 & 879 \\
\hline-159.31 & 19.58 & 907 & 60 & 38.45 & 19.31 & 1547 \\
\hline 65.89 & 19.41 & 952 & 122 & 67.99 & 19.11 & 985 \\
\hline 88.13 & 18.82 & -1168 & 372 & 88.75 & 19.29 & -1227 \\
\hline 68.20 & 18.04 & 742 & 103 & 68.76 & 18.11 & 635 \\
\hline
\end{tabular}




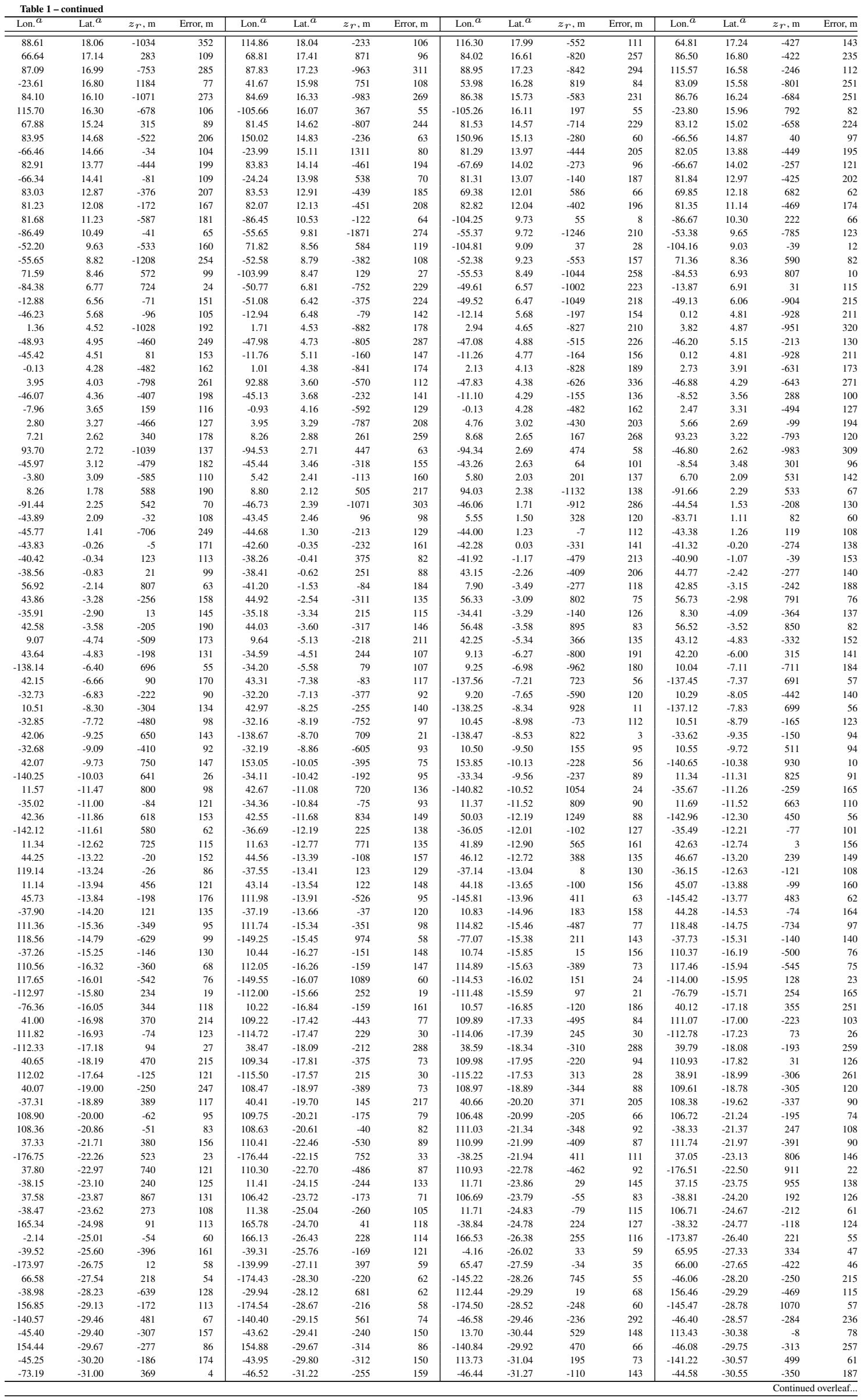




\begin{tabular}{|c|c|c|c|c|c|c|c|c|c|c|c|c|c|c|c|}
\hline Lon. $^{a}$ & Lat. $^{a}$ & $z_{r}, \mathrm{~m}$ & Error, $\mathrm{m}$ & Lon. $^{a}$ & Lat. $^{a}$ & $z_{r}, \mathrm{~m}$ & Error, $\mathrm{m}$ & Lon. $^{a}$ & Lat. $^{a}$ & $z_{r, \mathrm{~m}}$ & Error, $\mathrm{m}$ & Lon. $^{a}$ & Lat. ${ }^{a}$ & $z_{r}, \mathrm{~m}$ & Error, $\mathrm{m}$ \\
\hline-44.00 & $\begin{array}{l}-30.86 \\
\end{array}$ & -154 & 172 & $\begin{array}{l}-43.16 \\
\end{array}$ & -31.29 & -317 & 153 & 14.73 & -32.24 & 487 & 145 & 57.28 & $\begin{array}{l}-32.46 \\
\end{array}$ & 789 & 46 \\
\hline-48.55 & -32.19 & -888 & 256 & -48.00 & -31.98 & -737 & 223 & -47.03 & -32.16 & -598 & 177 & -45.99 & -32.15 & -472 & 147 \\
\hline-42.62 & -31.55 & 20 & 119 & -41.88 & -31.91 & 70 & 112 & -41.17 & -32.26 & -70 & 105 & 57.08 & -32.74 & 680 & 47 \\
\hline 57.70 & -32.74 & 548 & 49 & 111.33 & -32.76 & 43 & 91 & -48.91 & -33.25 & -992 & 271 & -47.90 & -32.83 & -889 & 210 \\
\hline-46.92 & -33.06 & -667 & 170 & -46.03 & -32.72 & -608 & 149 & -45.16 & -33.16 & -553 & 134 & -37.15 & -32.91 & 249 & 79 \\
\hline-49.83 & -34.04 & -1085 & 284 & -49.27 & -34.37 & -944 & 215 & -47.88 & -33.89 & -840 & 175 & -47.06 & -34.05 & -829 & 141 \\
\hline-46.29 & -34.43 & -758 & 119 & -43.88 & -33.81 & -421 & 113 & -42.98 & -34.27 & -340 & 102 & 15.85 & -34.63 & 338 & 85 \\
\hline 158.45 & -35.37 & -197 & 80 & 159.12 & -34.95 & -219 & 82 & 159.63 & -35.48 & -109 & 83 & -50.64 & -34.95 & -1126 & 244 \\
\hline-50.14 & -35.27 & -946 & 188 & -48.98 & -34.54 & -856 & 178 & -48.19 & -34.57 & -992 & 145 & -45.80 & -34.63 & -750 & 108 \\
\hline-45.27 & -34.86 & -647 & 101 & -42.52 & -34.51 & -582 & 102 & -42.30 & -34.62 & -420 & 97 & 23.82 & -36.44 & 225 & 92 \\
\hline 25.18 & -36.01 & -304 & 114 & 110.04 & -35.73 & -333 & 71 & 129.18 & -36.28 & -607 & 79 & 158.12 & -35.57 & 36 & 83 \\
\hline 159.48 & -35.54 & -81 & 87 & 159.77 & -35.94 & -171 & 79 & -49.63 & -35.59 & -890 & 154 & -48.99 & -36.00 & -891 & 126 \\
\hline-48.34 & -36.40 & -903 & 113 & 24.03 & -36.81 & 37 & 68 & 25.41 & -36.86 & -329 & 154 & 25.54 & -37.36 & -121 & 212 \\
\hline 123.72 & -36.94 & -334 & 66 & 129.41 & -36.61 & -603 & 73 & 129.62 & -36.92 & -797 & 74 & 135.56 & -37.20 & -796 & 90 \\
\hline 159.29 & -36.70 & -95 & 78 & 160.49 & -37.49 & 65 & 73 & 160.92 & -37.27 & -73 & 76 & -76.92 & -37.47 & 88 & 23 \\
\hline-50.52 & -36.93 & -1080 & 149 & -50.40 & -36.99 & -1049 & 142 & -47.84 & -36.71 & -725 & 99 & -47.29 & -37.04 & -789 & 97 \\
\hline 25.71 & -38.00 & -484 & 234 & 50.32 & -37.69 & 344 & 47 & 50.58 & -37.66 & 549 & 26 & 137.15 & -37.82 & -617 & 80 \\
\hline 160.29 & -37.60 & 82 & 73 & 161.17 & -38.34 & 38 & 78 & 161.82 & -38.01 & 16 & 79 & -76.64 & -37.53 & 26 & 31 \\
\hline-76.00 & -37.66 & 49 & 29 & -75.34 & -37.80 & -117 & 38 & -52.85 & -38.16 & -769 & 136 & 25.97 & -39.00 & -322 & 254 \\
\hline 139.30 & -39.17 & -702 & 70 & 150.21 & -39.22 & -333 & 107 & 150.87 & -39.23 & -359 & 100 & 160.84 & -38.51 & 114 & 73 \\
\hline 26.16 & -39.71 & -109 & 260 & 139.28 & -39.62 & -728 & 71 & 150.02 & -40.16 & -21 & 101 & -53.78 & -39.84 & -1018 & 141 \\
\hline-53.13 & -39.81 & -881 & 108 & 128.34 & -41.08 & -464 & 54 & 129.98 & -41.30 & -605 & 62 & 131.07 & -41.44 & -704 & 57 \\
\hline 141.04 & -40.89 & -935 & 78 & 150.12 & -41.17 & -124 & 103 & 150.63 & -41.43 & -121 & 93 & -54.78 & -41.10 & -1000 & 115 \\
\hline-54.37 & -41.13 & -991 & 121 & 132.18 & -41.59 & -495 & 55 & 132.96 & -41.70 & -467 & 55 & 150.03 & -41.69 & -128 & 102 \\
\hline 150.77 & -41.51 & 2 & 87 & -56.62 & -42.15 & -1149 & 134 & -56.03 & -42.26 & -1036 & 106 & -55.22 & -41.65 & -1108 & 141 \\
\hline-77.96 & -43.12 & 230 & 33 & -77.00 & -43.01 & 217 & 38 & -76.37 & -42.93 & 118 & 56 & -55.03 & -42.96 & -1176 & 138 \\
\hline-56.85 & -43.73 & -994 & 139 & -56.45 & -43.50 & -832 & 100 & -77.80 & -44.89 & 402 & 50 & -77.00 & -44.73 & 255 & 44 \\
\hline-76.39 & -44.61 & 112 & 53 & -57.78 & -46.44 & -791 & 210 & 100.39 & -47.41 & 159 & 16 & 100.54 & -47.48 & 229 & 15 \\
\hline-57.76 & -46.79 & -681 & 194 & -57.10 & -46.97 & -616 & 160 & -56.09 & -47.00 & -936 & 119 & 101.07 & -47.68 & 86 & 17 \\
\hline 101.85 & -47.86 & 82 & 11 & 127.00 & -48.24 & -257 & 52 & 127.58 & -48.31 & -660 & 37 & -57.10 & -47.52 & -405 & 175 \\
\hline 109.22 & -49.45 & -155 & 26 & 126.95 & -48.76 & -1047 & 38 & 151.97 & -49.33 & 563 & 72 & 109.44 & -49.52 & -261 & 21 \\
\hline 109.86 & -49.65 & -216 & 31 & 114.44 & -49.84 & -1079 & 43 & 114.97 & -49.96 & -1033 & 41 & 133.17 & -50.05 & -299 & 4 \\
\hline 133.65 & -50.08 & -272 & 4 & 151.24 & -50.12 & 435 & 76 & 151.75 & -49.57 & 491 & 71 & 151.22 & -51.79 & 528 & 69 \\
\hline 151.84 & -52.75 & 614 & 60 & 153.83 & -53.96 & 157 & 62 & 153.92 & -55.01 & 505 & 57 & 153.98 & -55.73 & 486 & 60 \\
\hline-57.84 & -56.23 & -530 & 92 & -57.28 & -56.35 & -123 & 97 & -56.01 & -56.63 & -473 & 126 & 92.72 & -60.46 & -876 & 138 \\
\hline-54.74 & -59.90 & 72 & 81 & 40.02 & -61.47 & -403 & 75 & 89.40 & -61.26 & -140 & 111 & 89.78 & -61.32 & -107 & 114 \\
\hline 91.17 & -60.82 & -285 & 111 & 92.23 & -61.30 & -453 & 124 & 92.73 & -61.03 & -474 & 124 & 100.75 & -61.07 & -352 & 102 \\
\hline 117.47 & -61.28 & -802 & 99 & 132.54 & -61.09 & -1032 & 102 & 54.84 & -62.33 & -363 & 89 & 61.66 & -62.42 & -143 & 96 \\
\hline 63.71 & -62.33 & -53 & 97 & 65.58 & -62.31 & -252 & 105 & 67.22 & -62.26 & -178 & 103 & 68.71 & -62.28 & -56 & 104 \\
\hline 70.50 & -62.06 & -92 & 116 & 72.11 & -62.48 & -391 & 140 & 90.44 & -61.92 & -119 & 118 & 91.03 & -61.71 & -279 & 120 \\
\hline 92.00 & -61.69 & -408 & 124 & 92.88 & -61.76 & -383 & 124 & 93.83 & -62.30 & -383 & 145 & 97.33 & -62.35 & -337 & 133 \\
\hline 100.70 & -61.79 & -515 & 117 & 140.06 & -61.67 & -109 & 86 & 151.09 & -62.27 & 263 & 63 & -64.07 & -61.88 & 610 & 59 \\
\hline 28.46 & -62.93 & -1024 & 112 & 52.44 & -63.42 & -430 & 113 & 53.03 & -63.21 & -436 & 109 & 53.92 & -62.78 & -492 & 98 \\
\hline 60.38 & -63.49 & -51 & 88 & 62.05 & -63.00 & -160 & 100 & 63.74 & -63.01 & -129 & 107 & 65.54 & -63.00 & -232 & 110 \\
\hline 67.26 & -63.00 & -212 & 111 & 68.72 & -63.00 & -186 & 120 & 70.53 & -62.99 & -155 & 123 & 72.14 & -63.02 & -306 & 134 \\
\hline 73.94 & -63.43 & -283 & 136 & 75.77 & -63.11 & -88 & 131 & 91.23 & -62.86 & -233 & 131 & 91.53 & -63.22 & -192 & 138 \\
\hline 97.34 & -62.55 & -199 & 132 & -66.39 & -63.49 & 732 & 79 & 52.34 & -63.54 & -455 & 119 & 60.42 & -63.53 & -112 & 92 \\
\hline 60.56 & -63.65 & -189 & 94 & 62.45 & -63.58 & -287 & 121 & 62.52 & -63.68 & -305 & 132 & 63.77 & -63.59 & -301 & 121 \\
\hline 65.49 & -63.68 & -289 & 130 & 67.30 & -63.74 & -206 & 130 & 68.74 & -63.70 & -24 & 137 & 70.55 & -63.61 & -79 & 135 \\
\hline 72.17 & -63.71 & -208 & 140 & 75.73 & -63.58 & -71 & 129 & 153.87 & -64.33 & -250 & 85 & -97.99 & -64.09 & 125 & 68 \\
\hline-70.09 & -64.42 & 211 & 86 & 153.59 & -64.55 & 158 & 75 & -97.98 & -64.85 & 62 & 69 & -73.98 & -65.10 & -31 & 70 \\
\hline-73.19 & -64.98 & -166 & 73 & -72.00 & -65.17 & -31 & 79 & -71.18 & -65.41 & 85 & 89 & -129.38 & -66.40 & 244 & 63 \\
\hline-72.81 & -66.28 & -232 & 96 & -72.10 & -65.95 & 193 & 93 & -70.81 & -65.52 & 163 & 94 & 6.01 & -67.01 & 133 & 106 \\
\hline-75.90 & -67.11 & -684 & 112 & -75.39 & -67.46 & -413 & 125 & -4.96 & -67.07 & 132 & 72 & 6.04 & -67.64 & 435 & 78 \\
\hline-78.82 & -68.35 & -610 & 97 & -77.99 & -68.05 & -681 & 96 & -77.27 & -67.80 & -611 & 102 & -75.50 & -67.51 & -387 & 124 \\
\hline-40.97 & -69.08 & -568 & 151 & -40.47 & -68.78 & -638 & 136 & 2.19 & 78.69 & 897 & 82 & 3.89 & 78.86 & 187 & 119 \\
\hline 2.19 & 78.69 & 897 & 82 & 6.36 & 76.66 & 1190 & 83 & 8.66 & 76.92 & 1388 & 96 & 14.52 & 75.41 & 734 & 249 \\
\hline-74.05 & 74.17 & -314 & 382 & 3.49 & 72.53 & 1111 & 35 & -132.60 & 73.08 & -2136 & 436 & -131.76 & 73.04 & -2176 & 464 \\
\hline-13.79 & 73.24 & 1335 & 85 & 2.30 & 72.27 & 1051 & 78 & 3.57 & 72.01 & 1204 & 75 & -143.24 & 71.72 & -1946 & 382 \\
\hline-134.10 & 71.90 & -2203 & 532 & -14.96 & 72.22 & 1728 & 100 & 2.30 & 72.27 & 1051 & 78 & 4.33 & 71.36 & 898 & 94 \\
\hline-17.64 & 70.69 & 882 & 96 & -17.31 & 71.00 & 1083 & 91 & 7.05 & 70.24 & 691 & 98 & 8.03 & 70.06 & 734 & 108 \\
\hline-19.17 & 70.08 & 1087 & 159 & -16.25 & 70.08 & 1236 & 60 & & & & & & & & \\
\hline
\end{tabular}


Table 2: 626 minimum residual depth measurements (upwards pointing triangles in Figure 1b of main text), averaged over $1^{\circ}$ bins. Crustal corrections have not been applied, but crust is deemed to be thinner than average, based upon constraints from nearby lines, absence of seamounts, presence of fracture zones and regional tectonic setting. Additional error of 100 metres was included during spherical harmonic fitting to account for uncertainty caused by the lack of crustal correction.

\begin{tabular}{|c|c|c|c|c|c|c|c|c|}
\hline Lon $^{a}$ & Lat. ${ }^{a}$ & $z_{r}, \mathrm{~m}$ & Error, $\mathrm{m}$ & Lon. $^{a}$ & Lat. $^{a}$ & $z_{r}, \mathrm{~m}$ & Error, $\mathrm{m}$ & Lon $^{a}$ \\
\hline 3.82 & 69.69 & 972 & 16 & 3.46 & 68.80 & 1237 & 10 & 3.62 \\
\hline-140.58 & 58.06 & -416 & 47 & -51.63 & 54.39 & -92 & 127 & -51.00 \\
\hline-50.26 & 53.34 & -129 & 90 & -41.52 & 48.51 & 687 & 32 & -42.99 \\
\hline-7.62 & 45.49 & -526 & 32 & -5.12 & 44.71 & -2950 & 132 & -57.16 \\
\hline 31.21 & 42.63 & -1776 & 367 & -134.61 & 42.91 & -88 & 2 & -134.00 \\
\hline-132.00 & 43.16 & -195 & 4 & -131.00 & 43.06 & -254 & 5 & -130.00 \\
\hline-128.00 & 42.72 & 39 & 2 & -127.00 & 42.60 & 154 & 0 & -126.31 \\
\hline-53.60 & 43.24 & -1147 & 164 & 30.45 & 42.28 & -1665 & 358 & 30.72 \\
\hline-125.48 & 42.42 & -72 & 9 & -59.00 & 41.85 & -1605 & 119 & -56.33 \\
\hline-46.28 & 41.86 & -592 & 46 & -64.09 & 41.45 & -457 & 136 & -59.49 \\
\hline-55.77 & 41.24 & -1475 & 94 & -55.24 & 40.74 & -1368 & 77 & -12.92 \\
\hline-58.60 & 39.70 & -1111 & 61 & -58.10 & 40.14 & -1509 & 86 & -56.73 \\
\hline-54.84 & 40.17 & -1186 & 57 & -54.23 & 39.76 & -1251 & 54 & -48.61 \\
\hline-47.23 & 39.94 & 42 & 32 & 144.40 & 39.08 & -1193 & 29 & -54.92 \\
\hline-53.45 & 38.99 & -447 & 16 & 149.19 & 38.23 & -522 & 7 & 144.00 \\
\hline-13.62 & 33.93 & -312 & 57 & -12.00 & 33.65 & -450 & 67 & 143.66 \\
\hline-13.93 & 33.07 & -79 & 49 & -13.09 & 33.11 & 107 & 49 & -12.00 \\
\hline-14.80 & 32.34 & 159 & 36 & -14.03 & 32.19 & 162 & 42 & -13.00 \\
\hline 143.46 & 31.21 & -489 & 5 & -15.99 & 30.79 & 252 & 43 & -14.99 \\
\hline-15.66 & 29.70 & 387 & 74 & -15.24 & 30.21 & 829 & 60 & -15.88 \\
\hline-17.06 & 27.62 & 239 & 75 & -16.48 & 27.51 & 14 & 95 & -61.55 \\
\hline-16.99 & 27.12 & 195 & 78 & -16.30 & 27.17 & -213 & 113 & -61.65 \\
\hline-18.00 & 26.25 & 838 & 46 & -57.75 & 25.34 & -933 & 6 & -157.52 \\
\hline-17.76 & 23.55 & -179 & 270 & -17.46 & 23.53 & 129 & 306 & -93.81 \\
\hline 37.74 & 22.43 & 1190 & 1 & -94.67 & 22.14 & -1857 & 259 & -94.31 \\
\hline-17.80 & 22.44 & -544 & 307 & 38.59 & 20.52 & 1713 & 31 & -65.51 \\
\hline 118.11 & 18.53 & -657 & 40 & 123.19 & 18.62 & -616 & 22 & 123.61 \\
\hline 117.77 & 18.43 & -627 & 36 & 122.84 & 18.48 & -746 & 37 & 133.07 \\
\hline 136.44 & 18.00 & -393 & 1 & 137.00 & 18.00 & -588 & 1 & 138.00 \\
\hline 140.07 & 17.98 & -636 & 2 & 141.00 & 17.98 & -814 & 10 & 141.69 \\
\hline 144.79 & 18.15 & -565 & 2 & 156.44 & 17.78 & -158 & 5 & 156.66 \\
\hline 158.62 & 17.59 & -138 & 5 & 84.64 & 17.05 & -919 & 210 & 157.11 \\
\hline 159.56 & 16.91 & -159 & 5 & -65.62 & 15.65 & 188 & 36 & 84.55 \\
\hline-76.25 & 14.58 & 184 & 40 & -74.99 & 14.66 & 734 & 20 & -74.50 \\
\hline 114.75 & 13.73 & -538 & 5 & -76.65 & 13.78 & 412 & 34 & -76.40 \\
\hline-74.00 & 14.21 & 738 & 26 & -73.03 & 13.81 & -7 & 54 & -57.81 \\
\hline 113.08 & 12.66 & -839 & 16 & 114.24 & 13.00 & -588 & 7 & 115.14 \\
\hline 156.00 & 13.16 & -499 & 6 & 156.53 & 13.32 & -577 & 7 & -77.03 \\
\hline 113.35 & 12.30 & -729 & 11 & 113.63 & 11.92 & -688 & 10 & 114.91 \\
\hline-103.00 & 12.15 & -62 & 0 & -102.40 & 12.23 & 93 & 0 & 82.81 \\
\hline 155.53 & 11.16 & -110 & 3 & -53.97 & 9.84 & -861 & 62 & -50.20 \\
\hline 164.32 & 6.16 & 546 & 6 & 165.00 & 6.22 & 371 & 8 & 166.00 \\
\hline 167.50 & 6.45 & -1585 & 7 & -43.63 & 5.84 & 256 & 20 & -43.42 \\
\hline 5.74 & 3.56 & -294 & 348 & 51.01 & 3.78 & -702 & 30 & 51.83 \\
\hline-44.35 & 4.24 & -112 & 46 & -3.94 & 3.84 & -496 & 85 & 50.98 \\
\hline-42.44 & 3.33 & 152 & 25 & -4.51 & 2.95 & -1889 & 133 & 51.38 \\
\hline-92.67 & 2.21 & 757 & 4 & -83.74 & 2.00 & -148 & 3 & 6.93 \\
\hline 7.42 & 0.42 & 339 & 94 & 7.51 & 0.33 & 368 & 92 & -42.87 \\
\hline 42.42 & -2.39 & -619 & 187 & 44.13 & -2.07 & -468 & 108 & 42.20 \\
\hline 45.17 & -3.58 & -724 & 64 & -34.56 & -3.55 & 189 & 44 & 8.49 \\
\hline 45.66 & -4.67 & -463 & 44 & 80.17 & -5.49 & -803 & 30 & 9.97 \\
\hline 128.13 & -6.20 & -2470 & 15 & 128.21 & -6.55 & -2261 & 15 & 42.04 \\
\hline 42.19 & -11.00 & 544 & 106 & -141.91 & -11.43 & 807 & 3 & 50.51 \\
\hline-144.68 & -13.42 & 468 & 2 & -144.09 & -13.13 & 482 & 2 & -143.34 \\
\hline-149.38 & -15.73 & 920 & 3 & -37.10 & -16.04 & -373 & 64 & -149.79 \\
\hline 3.55 & -17.99 & -392 & 7 & -150.69 & -18.39 & 1112 & 3 & -150.39 \\
\hline 8.00 & -19.08 & -470 & 20 & 8.55 & -19.19 & -419 & 23 & -150.78 \\
\hline 43.09 & -24.25 & 570 & 51 & 43.34 & -24.65 & 518 & 42 & -11.74 \\
\hline 155.74 & -29.58 & -316 & 43 & -73.52 & -31.00 & 451 & 9 & 123.13 \\
\hline 127.40 & -36.07 & -627 & 14 & 128.07 & -36.24 & -798 & 18 & 130.01 \\
\hline-31.21 & -36.48 & 353 & 9 & 123.33 & -36.63 & -442 & 11 & 127.22 \\
\hline 130.90 & -36.88 & -946 & 19 & 131.81 & -37.02 & -1033 & 21 & 132.73 \\
\hline-30.82 & -36.55 & 306 & 8 & -30.00 & -36.69 & 279 & 10 & -29.14 \\
\hline 130.17 & -37.70 & -1085 & 12 & 131.48 & -37.92 & -1390 & 18 & 131.54 \\
\hline 138.08 & -38.19 & -818 & 12 & 138.39 & -38.62 & -641 & 7 & 139.50 \\
\hline 150.58 & -40.03 & -512 & 52 & 129.00 & -41.17 & -803 & 0 & 140.43 \\
\hline 127.35 & -42.50 & -723 & 0 & 127.81 & -42.06 & -802 & 0 & 131.49 \\
\hline 134.82 & -42.19 & -638 & 0 & 142.16 & -42.08 & -507 & 8 & 142.80 \\
\hline 127.19 & -42.50 & -730 & 0 & 135.05 & -43.00 & -621 & 0 & 141.43 \\
\hline 143.20 & -42.85 & -360 & 8 & 143.74 & -43.27 & -351 & 15 & 135.12 \\
\hline 143.70 & -44.03 & -433 & 8 & 152.01 & -43.91 & 29 & 26 & 153.00 \\
\hline 163.03 & -44.01 & 80 & 12 & 128.43 & -45.20 & -620 & 0 & 135.19 \\
\hline 149.47 & -45.33 & 93 & 29 & 149.54 & -45.26 & 155 & 27 & 151.49 \\
\hline 163.39 & -44.52 & -36 & 16 & 128.48 & -45.64 & -541 & 0 & 128.97 \\
\hline 135.27 & -46.00 & -439 & 0 & 144.35 & -45.95 & -306 & 4 & 144.58 \\
\hline 150.65 & -46.37 & 194 & 12 & 130.13 & -47.00 & -551 & 0 & 135.31 \\
\hline 130.24 & -48.00 & -521 & 0 & 151.89 & -47.82 & 1 & 20 & 154.15 \\
\hline 130.30 & -48.51 & 388 & 0 & 147.29 & -49.22 & -18 & 7 & 153.06 \\
\hline 154.74 & -48.71 & 367 & 4 & 156.19 & -49.24 & -335 & 12 & 162.28 \\
\hline-51.32 & -48.92 & -1333 & 20 & -45.81 & -49.11 & -826 & 9 & -44.77 \\
\hline 115.52 & -50.08 & -320 & 0 & 153.31 & -49.84 & -247 & 16 & 154.03 \\
\hline 156.47 & -49.53 & -337 & 18 & 156.97 & -50.03 & -232 & 13 & 158.32 \\
\hline 160.46 & -50.47 & 329 & 0 & 161.00 & -50.16 & 94 & 4 & 161.82 \\
\hline 157.47 & -50.54 & -404 & 19 & 157.93 & -51.01 & -107 & 9 & 158.88 \\
\hline-39.69 & -51.36 & -171 & 73 & -39.33 & -51.09 & -68 & 52 & 151.59 \\
\hline-40.20 & -51.73 & -339 & 86 & 153.18 & -53.41 & -15 & 6 & 153.75 \\
\hline 157.88 & -54.48 & -462 & 8 & 158.17 & -54.61 & -77 & 5 & 159.38 \\
\hline 156.84 & -56.50 & 181 & 5 & 159.35 & -56.50 & -65 & 9 & 159.79 \\
\hline-29.00 & -57.44 & -243 & 9 & -28.16 & -57.41 & 139 & 11 & -22.95 \\
\hline
\end{tabular}




\begin{tabular}{|c|c|c|c|c|c|c|c|c|c|c|c|c|c|c|c|}
\hline Lon. $^{a}$ & Lat. $^{a}$ & $z_{r}, \mathrm{~m}$ & Error, $\mathrm{m}$ & Lon. $^{a}$ & Lat. ${ }^{a}$ & $z_{r}, \mathrm{~m}$ & Error, $\mathrm{m}$ & Lon. $^{a}$ & Lat. $^{a}$ & $z_{r}, \mathrm{~m}$ & Error, $\mathrm{m}$ & Lon. $^{a}$ & Lat. ${ }^{a}$ & $z_{r}, \mathrm{~m}$ & Error, $\mathrm{m}$ \\
\hline-32.59 & $\begin{array}{l}-57.60 \\
\end{array}$ & 59 & 8 & -32.00 & $\begin{array}{l}-57.57 \\
\end{array}$ & -278 & 4 & -31.00 & -57.53 & $\begin{array}{l}-281 \\
\end{array}$ & 2 & -30.40 & -57.51 & -185 & 1 \\
\hline-31.98 & -59.09 & 487 & 1 & -31.00 & -59.20 & -21 & 1 & -30.00 & -59.30 & 232 & 1 & -29.27 & -59.38 & 941 & 0 \\
\hline 90.88 & -60.46 & -232 & 43 & 97.24 & -60.40 & -284 & 37 & 132.50 & -60.46 & -718 & 21 & -61.40 & -60.47 & 230 & 5 \\
\hline-55.71 & -60.26 & -333 & 29 & -22.92 & -60.05 & 119 & 2 & -22.30 & -60.11 & 168 & 1 & -2.06 & -60.03 & -566 & 11 \\
\hline 46.87 & -61.23 & -573 & 21 & 97.27 & -61.00 & -336 & 46 & 107.33 & -61.28 & -420 & 19 & 112.23 & -61.21 & -715 & 35 \\
\hline 126.02 & -61.28 & -997 & 46 & 131.46 & -61.46 & -941 & 46 & 140.04 & -61.13 & -281 & 20 & 140.84 & -61.08 & -372 & 22 \\
\hline 157.25 & -61.17 & 566 & 0 & 157.61 & -61.42 & 472 & 0 & 168.24 & -61.07 & 383 & 6 & 169.00 & -61.30 & 766 & 1 \\
\hline 169.58 & -61.47 & 569 & 3 & -61.12 & -60.69 & 370 & 5 & 25.12 & -62.46 & -696 & 28 & 28.49 & -62.31 & -915 & 33 \\
\hline 40.02 & -61.96 & -568 & 22 & 46.83 & -62.01 & -444 & 41 & 53.34 & -62.32 & -768 & 34 & 53.63 & -62.11 & -765 & 33 \\
\hline 107.19 & -61.80 & -498 & 27 & 112.26 & -61.52 & -972 & 48 & 117.45 & -61.61 & -985 & 49 & 126.07 & -62.00 & -901 & 62 \\
\hline 131.48 & -62.02 & -689 & 53 & 140.67 & -61.56 & 54 & 16 & 141.81 & -61.90 & -275 & 23 & 150.24 & -62.06 & 373 & 4 \\
\hline 151.75 & -62.44 & 210 & 4 & 158.12 & -61.78 & 514 & 0 & 158.82 & -62.27 & 580 & 0 & 170.14 & -61.64 & 779 & 2 \\
\hline 170.97 & -61.87 & 850 & 3 & 172.00 & -62.15 & 210 & 3 & 172.56 & -62.30 & 536 & 0 & 24.33 & -63.31 & -843 & 35 \\
\hline 24.80 & -62.81 & -681 & 27 & 34.21 & -63.11 & -924 & 40 & 41.77 & -63.34 & -560 & 29 & 46.79 & -62.94 & -420 & 67 \\
\hline 57.05 & -63.08 & -458 & 35 & 126.11 & -62.55 & -702 & 66 & 131.50 & -62.72 & -912 & 65 & 147.33 & -63.09 & 102 & 14 \\
\hline 152.26 & -62.56 & 143 & 3 & 152.65 & -62.66 & 71 & 1 & 159.32 & -62.62 & 556 & 0 & 160.00 & -63.09 & 625 & 0 \\
\hline 163.15 & -63.47 & 552 & 0 & 164.00 & -63.39 & 661 & 0 & 164.54 & -63.34 & 596 & 0 & 166.44 & -63.03 & 976 & 0 \\
\hline 166.75 & -63.30 & 1182 & 0 & 23.36 & -64.36 & -574 & 30 & 23.82 & -63.86 & -718 & 33 & 25.44 & -64.30 & -866 & 45 \\
\hline 27.26 & -64.13 & -1209 & 59 & 28.42 & -64.01 & -1228 & 56 & 34.31 & -63.84 & -886 & 43 & 39.10 & -64.46 & -817 & 45 \\
\hline 40.08 & -64.38 & -693 & 44 & 41.00 & -64.10 & -564 & 41 & 41.97 & -64.16 & -397 & 39 & 42.86 & -64.11 & -336 & 32 \\
\hline 56.49 & -63.99 & -405 & 43 & 56.65 & -63.73 & -510 & 42 & 73.95 & -63.63 & -132 & 66 & 92.08 & -63.88 & 62 & 75 \\
\hline 162.00 & -63.57 & 557 & 0 & 162.65 & -63.51 & 411 & 0 & 167.25 & -63.71 & 814 & 0 & 167.71 & -64.10 & 701 & 0 \\
\hline-75.11 & -64.46 & 12 & 14 & -70.70 & -64.26 & -198 & 28 & 22.40 & -65.39 & -813 & 50 & 22.86 & -64.89 & -730 & 42 \\
\hline 25.48 & -64.80 & -897 & 52 & 25.52 & -65.30 & -1126 & 75 & 27.07 & -65.00 & -1279 & 71 & 28.38 & -64.78 & -1408 & 72 \\
\hline 37.27 & -64.64 & -910 & 47 & 38.00 & -64.57 & -896 & 46 & 38.61 & -64.51 & -1165 & 61 & 40.20 & -64.50 & -433 & 37 \\
\hline 153.49 & -64.62 & -32 & 21 & 172.06 & -65.43 & 452 & 10 & 172.56 & -65.36 & 296 & 13 & -74.76 & -64.61 & -71 & 16 \\
\hline-69.62 & -64.53 & 94 & 41 & -69.47 & -64.57 & 35 & 48 & -27.51 & -65.20 & -931 & 44 & -27.20 & -65.36 & -728 & 36 \\
\hline 21.43 & -66.43 & -708 & 65 & 21.89 & -65.93 & -780 & 59 & 25.57 & -66.00 & -1008 & 86 & 26.85 & -66.00 & -1192 & 78 \\
\hline 171.46 & -65.52 & 462 & 16 & 171.55 & -65.51 & 507 & 9 & -128.01 & -66.02 & 247 & 5 & -127.11 & -66.30 & 327 & 5 \\
\hline-119.99 & -66.15 & 48 & 14 & -104.53 & -66.24 & -210 & 50 & -84.61 & -66.15 & -519 & 38 & -75.55 & -66.47 & -337 & 21 \\
\hline-75.22 & -66.22 & -156 & 16 & -74.25 & -66.42 & -987 & 51 & -26.70 & -65.60 & -624 & 33 & -26.00 & -65.94 & -176 & 17 \\
\hline-25.18 & -66.34 & -130 & 16 & 21.34 & -66.52 & -634 & 62 & 23.09 & -66.77 & -1207 & 86 & 24.07 & -66.99 & -1201 & 95 \\
\hline 24.98 & -67.00 & -1104 & 95 & 25.86 & -66.77 & -1070 & 97 & 26.91 & -66.62 & -1088 & 85 & 28.00 & -66.61 & -958 & 84 \\
\hline 28.99 & -66.59 & -808 & 86 & 29.64 & -66.58 & -780 & 88 & -132.51 & -67.34 & 42 & 13 & -132.38 & -67.42 & 160 & 11 \\
\hline-130.80 & -67.02 & 352 & 5 & -130.00 & -67.01 & 236 & 11 & -128.96 & -66.94 & 326 & 10 & -128.00 & -67.20 & 554 & 8 \\
\hline-126.99 & -67.25 & 617 & 8 & -126.25 & -67.13 & 717 & 5 & -119.98 & -66.51 & 97 & 13 & -109.92 & -67.02 & 91 & 29 \\
\hline-104.54 & -67.00 & -358 & 55 & -84.52 & -66.58 & -666 & 47 & -84.48 & -66.72 & -565 & 46 & -81.17 & -67.43 & -703 & 31 \\
\hline-80.00 & -66.75 & -576 & 34 & -79.00 & -67.00 & -810 & 46 & -78.00 & -67.25 & -760 & 55 & -77.00 & -67.40 & -736 & 57 \\
\hline-73.95 & -66.77 & -833 & 55 & -73.44 & -66.57 & -588 & 41 & -24.68 & -66.59 & -219 & 19 & -24.00 & -66.92 & -514 & 29 \\
\hline-23.16 & -67.34 & -475 & 27 & 25.46 & -67.51 & -1052 & 118 & 25.55 & -67.54 & -1415 & 119 & -131.87 & -67.73 & 299 & 10 \\
\hline-131.04 & -68.23 & 548 & 7 & -130.08 & -68.00 & 690 & 6 & -126.80 & -67.74 & 806 & 7 & -125.91 & -67.94 & 831 & 10 \\
\hline-125.08 & -67.80 & 935 & 7 & -124.06 & -67.73 & 947 & 8 & -109.97 & -67.71 & 289 & 31 & -104.55 & -68.00 & -316 & 56 \\
\hline-81.80 & -68.46 & -884 & 48 & -80.98 & -68.08 & -944 & 43 & -80.00 & -67.95 & -840 & 30 & -39.98 & -68.49 & -808 & 60 \\
\hline-28.93 & -68.13 & -578 & 41 & -28.00 & -68.13 & -531 & 37 & -27.00 & -68.12 & -459 & 33 & -26.32 & -68.12 & -745 & 45 \\
\hline-22.66 & -67.58 & -670 & 35 & -22.00 & -67.91 & -641 & 34 & -21.14 & -68.33 & -725 & 39 & -4.62 & -67.52 & -143 & 23 \\
\hline-1.64 & -67.77 & 17 & 28 & -1.45 & -67.66 & 13 & 26 & 176.04 & -69.28 & 510 & 17 & -130.55 & -68.53 & 543 & 11 \\
\hline-129.78 & -68.60 & 722 & 10 & -129.41 & -68.81 & 754 & 12 & -124.87 & -68.66 & 850 & 13 & -104.55 & -69.00 & -287 & 68 \\
\hline-98.85 & -69.06 & -421 & 44 & -98.07 & -68.92 & -431 & 41 & -89.66 & -69.39 & -155 & 41 & -89.00 & -69.31 & -494 & 50 \\
\hline-88.00 & -69.20 & -361 & 54 & -87.00 & -69.08 & -306 & 53 & -86.00 & -68.96 & -226 & 51 & -85.00 & -68.85 & -281 & 43 \\
\hline-83.94 & -68.72 & -552 & 38 & -83.00 & -68.61 & -646 & 49 & -82.30 & -68.53 & -869 & 55 & -80.82 & -68.50 & -1126 & 63 \\
\hline-79.62 & -68.63 & -675 & 60 & -79.38 & -68.54 & -626 & 45 & -31.55 & -69.49 & -858 & 66 & -31.00 & -69.41 & -875 & 66 \\
\hline-30.00 & -69.26 & -872 & 64 & -29.00 & -69.11 & -770 & 55 & -28.35 & -69.01 & -558 & 40 & -20.65 & -68.57 & -527 & 33 \\
\hline-20.00 & -68.89 & -601 & 39 & -19.09 & -69.33 & -592 & 44 & -104.56 & -69.72 & -292 & 81 & -103.51 & -69.99 & -276 & 59 \\
\hline-103.00 & -69.61 & -253 & 53 & -102.00 & -69.50 & -145 & 50 & -101.00 & -69.50 & -199 & 51 & -100.00 & -69.50 & -100 & 43 \\
\hline-99.00 & -69.50 & -347 & 51 & -98.00 & -69.50 & -274 & 43 & -97.00 & -69.50 & -173 & 36 & -96.48 & -69.50 & -946 & 36 \\
\hline-33.91 & -69.85 & -798 & 73 & -33.00 & -69.71 & -834 & 71 & -32.05 & -69.57 & -834 & 69 & -18.58 & -69.52 & -669 & 48 \\
\hline-18.00 & -69.65 & -488 & 41 & -17.00 & -69.87 & -316 & 35 & -16.45 & -69.99 & -514 & 43 & 121.35 & 88.56 & -158 & 65 \\
\hline 125.00 & 88.72 & -268 & 73 & 129.20 & 88.92 & 185 & 51 & 100.50 & 87.59 & -355 & 64 & 105.00 & 87.80 & -553 & 77 \\
\hline 110.00 & 88.03 & -342 & 70 & 115.00 & 88.26 & -589 & 83 & 118.80 & 88.44 & -392 & 76 & 77.15 & 86.52 & 149 & 2 \\
\hline 80.00 & 86.65 & 612 & 2 & 85.00 & 86.88 & 475 & 2 & 90.00 & 87.11 & -248 & 33 & 95.00 & 87.34 & -307 & 47 \\
\hline 97.95 & 87.47 & -599 & 73 & 15.35 & 85.60 & -1086 & 3 & 74.75 & 86.40 & -674 & 1 & 16.55 & 85.25 & -349 & 16 \\
\hline 18.30 & 84.75 & -205 & 9 & 20.85 & 84.01 & -231 & 50 & 25.77 & 83.65 & -318 & 74 & 27.65 & 83.58 & -407 & 80 \\
\hline 24.35 & 83.00 & -395 & 81 & 28.90 & 82.98 & -692 & 100 & 26.75 & 82.31 & -682 & 105 & 29.40 & 82.07 & -343 & 106 \\
\hline-0.40 & 79.70 & 118 & 66 & -3.35 & 79.98 & 276 & 85 & -0.40 & 79.70 & 118 & 66 & -1.90 & 77.61 & -36 & 91 \\
\hline-2.70 & 77.76 & -58 & 93 & -1.90 & 77.61 & -36 & 91 & 0.65 & 77.15 & 284 & 62 & 0.65 & 77.15 & 284 & 62 \\
\hline 5.35 & 76.31 & 956 & 21 & -147.54 & 72.17 & -2207 & 274 & -140.64 & 71.65 & -2181 & 363 & -132.22 & 72.05 & -1610 & 453 \\
\hline-140.52 & 71.39 & -2457 & 425 & -135.26 & 71.34 & -2498 & 557 & -103.53 & -70.01 & -343 & 64 & -16.36 & -70.01 & -612 & 46 \\
\hline-158.75 & -72.39 & 218 & 21 & -155.44 & -72.41 & -102 & 37 & & & & & & & & \\
\hline
\end{tabular}


Table 3: 488 maximum residual depth measurements (downwards pointing triangles in Figure $1 \mathrm{~b}$ of main text), averaged over $1^{\circ}$ bins. Crustal corrections have not been applied, but crust is deemed to be thicker than average, based upon constraints from nearby lines, presence of seamounts and regional tectonic setting. Additional error of 100 metres was included during spherical harmonic fitting to account for uncertainty caused by the lack of crustal correction.

\begin{tabular}{|c|c|c|c|c|c|c|c|c|}
\hline Lon. $^{a}$ & Lat. ${ }^{a}$ & $z_{r}, \mathrm{~m}$ & Error, $\mathrm{m}$ & Lon. $^{a}$ & Lat. ${ }^{a}$ & $z_{r}, \mathrm{~m}$ & Error, $\mathrm{m}$ & Lon. $^{a}$ \\
\hline $\begin{array}{l}-18.40 \\
\end{array}$ & 69.98 & 991 & 86 & 2.99 & 68.56 & 1473 & 48 & 3.30 \\
\hline-0.68 & 67.71 & 1215 & 121 & -0.12 & 64.18 & 727 & 142 & -23.29 \\
\hline-36.11 & 62.68 & 1516 & 20 & -23.33 & 62.99 & 2191 & 25 & -39.50 \\
\hline-35.00 & 62.32 & 1203 & 20 & -34.01 & 62.11 & 1131 & 16 & -33.00 \\
\hline-31.00 & 62.01 & 1635 & 5 & -30.00 & 61.94 & 1675 & 5 & -29.00 \\
\hline-57.52 & 60.53 & -24 & 64 & -38.70 & 61.41 & 1396 & 31 & -38.00 \\
\hline-36.02 & 60.58 & 1167 & 12 & -35.00 & 60.53 & 1321 & 7 & -34.00 \\
\hline-28.79 & 61.27 & 2245 & 72 & -27.00 & 61.29 & 2028 & 5 & -23.00 \\
\hline-21.00 & 61.26 & 1644 & 19 & -19.97 & 61.13 & 1318 & 27 & -19.02 \\
\hline-32.00 & 60.42 & 1386 & 3 & -31.00 & 60.37 & 1735 & 2 & -30.00 \\
\hline-28.00 & 60.20 & 1726 & 3 & -27.00 & 60.14 & 1560 & 7 & -26.00 \\
\hline-24.00 & 59.89 & 1616 & 12 & -23.00 & 59.83 & 1417 & 21 & -22.29 \\
\hline-18.21 & 60.22 & 1735 & 15 & -59.50 & 59.31 & 1422 & 60 & -140.05 \\
\hline -139.97 & 57.32 & -352 & 126 & -31.78 & 57.48 & 1521 & 0 & 168.39 \\
\hline-176.00 & 55.99 & -576 & 123 & -175.26 & 56.38 & -610 & 126 & -173.87 \\
\hline-178.69 & 55.17 & -308 & 116 & -177.96 & 54.96 & -834 & 139 & -177.21 \\
\hline-135.63 & 54.53 & 185 & 125 & -135.32 & 54.63 & 221 & 79 & -42.91 \\
\hline-135.99 & 54.20 & 618 & 105 & 177.44 & 53.39 & -204 & 111 & -175.95 \\
\hline-141.17 & 52.60 & 260 & 53 & -138.75 & 53.13 & 17 & 80 & -133.90 \\
\hline-148.37 & 50.73 & 119 & 27 & -145.18 & 51.38 & 223 & 31 & -169.80 \\
\hline-126.07 & 46.93 & -314 & 112 & -9.85 & 46.89 & -62 & 85 & -143.18 \\
\hline-127.03 & 46.50 & 237 & 104 & -125.97 & 46.23 & -191 & 105 & -15.35 \\
\hline-132.63 & 44.70 & -95 & 66 & -163.78 & 44.30 & -184 & 20 & -143.12 \\
\hline-137.10 & 43.75 & 92 & 48 & -125.83 & 44.11 & 121 & 67 & -134.45 \\
\hline-128.41 & 40.90 & 292 & 110 & -126.67 & 40.97 & 319 & 100 & -125.79 \\
\hline 145.38 & 39.88 & -165 & 44 & 146.00 & 39.78 & -22 & 44 & -172.98 \\
\hline-128.18 & 40.07 & -380 & 58 & -67.12 & 39.83 & -1020 & 220 & -65.27 \\
\hline-136.17 & 38.90 & 5 & 16 & -128.00 & 38.58 & -221 & 47 & -124.92 \\
\hline-70.00 & 38.83 & -319 & 170 & -68.94 & 39.16 & -278 & 156 & -68.21 \\
\hline-39.04 & 38.75 & 23 & 74 & -37.12 & 39.12 & 629 & 123 & -35.29 \\
\hline-125.02 & 38.14 & -418 & 72 & -71.91 & 38.02 & -480 & 175 & -71.24 \\
\hline-66.17 & 38.23 & 302 & 123 & -64.56 & 37.52 & -119 & 23 & -64.00 \\
\hline-62.29 & 37.55 & -705 & 43 & -60.82 & 37.61 & -680 & 35 & -60.00 \\
\hline-157.03 & 37.15 & -241 & 39 & -143.12 & 37.25 & -218 & 32 & -125.87 \\
\hline-72.47 & 36.96 & -468 & 155 & -70.58 & 37.26 & -281 & 70 & -69.22 \\
\hline-67.00 & 36.69 & -299 & 31 & -66.00 & 37.02 & -269 & 30 & -65.05 \\
\hline-61.31 & 37.44 & -397 & 25 & 17.86 & 36.00 & -1283 & 228 & -125.89 \\
\hline-72.29 & 35.66 & -438 & 85 & -69.94 & 36.06 & -148 & 48 & -68.90 \\
\hline-142.52 & 35.08 & -101 & 28 & -125.10 & 34.98 & -187 & 48 & -123.27 \\
\hline-69.42 & 34.78 & -366 & 22 & -26.04 & 35.29 & 1393 & 37 & -173.05 \\
\hline-126.03 & 34.48 & -322 & 43 & -122.13 & 34.37 & 308 & 71 & -74.76 \\
\hline-70.16 & 34.27 & -397 & 24 & -69.22 & 33.91 & -199 & 15 & -63.03 \\
\hline 152.51 & 32.52 & -396 & 44 & -127.07 & 32.83 & 76 & 42 & -125.93 \\
\hline-74.97 & 32.88 & -1041 & 130 & -69.94 & 33.01 & -470 & 23 & -57.50 \\
\hline 151.76 & 32.49 & -448 & 33 & -172.07 & 32.13 & -241 & 42 & -154.65 \\
\hline-73.95 & 31.60 & -801 & 52 & -71.78 & 32.45 & -735 & 35 & -70.61 \\
\hline-31.14 & 31.85 & 527 & 60 & -135.40 & 31.08 & 423 & 71 & -120.90 \\
\hline-75.01 & 30.99 & -68 & 94 & -74.33 & 31.41 & -652 & 62 & -72.95 \\
\hline 135.07 & 29.74 & -822 & 53 & -152.68 & 30.45 & -61 & 27 & -121.73 \\
\hline-74.00 & 30.13 & -362 & 65 & -73.42 & 30.46 & -725 & 50 & 136.53 \\
\hline-152.47 & 29.33 & -374 & 22 & -117.58 & 29.13 & 370 & 68 & -117.41 \\
\hline-74.78 & 28.63 & -302 & 41 & -74.00 & 29.01 & -355 & 53 & -73.34 \\
\hline-174.18 & 28.34 & -94 & 74 & -127.42 & 28.08 & -238 & 26 & -75.80 \\
\hline-169.08 & 26.70 & 792 & 27 & -121.58 & 27.40 & -238 & 21 & -76.00 \\
\hline-74.15 & 26.79 & 13 & 42 & -70.22 & 27.50 & -475 & 17 & -69.14 \\
\hline-163.70 & 25.50 & 502 & 8 & -74.11 & 26.34 & -27 & 23 & -72.45 \\
\hline-67.59 & 25.77 & -432 & 66 & -178.02 & 25.44 & 164 & 40 & -160.32 \\
\hline-92.41 & 25.13 & -1857 & 347 & -90.58 & 25.32 & -1371 & 205 & -90.49 \\
\hline-56.00 & 24.70 & -829 & 5 & -55.37 & 24.53 & -661 & 2 & 128.12 \\
\hline-165.48 & 24.34 & 492 & 99 & -160.48 & 23.96 & 683 & 0 & -156.13 \\
\hline-54.88 & 24.40 & -366 & 2 & -51.46 & 23.51 & -236 & 1 & 130.97 \\
\hline-156.58 & 23.10 & 1189 & 12 & -155.90 & 22.80 & 1200 & 12 & -151.00 \\
\hline-137.50 & 23.07 & -98 & 34 & -58.25 & 23.49 & -343 & 73 & -50.00 \\
\hline-48.00 & 22.80 & 187 & 1 & 65.50 & 22.49 & -235 & 190 & -166.12 \\
\hline-116.05 & 21.97 & 77 & 36 & 131.88 & 20.10 & -747 & 42 & -161.42 \\
\hline 67.48 & 18.97 & 642 & 50 & 138.35 & 19.05 & -741 & 12 & -177.32 \\
\hline-128.50 & 19.37 & 10 & 35 & 69.70 & 17.62 & 507 & 46 & 140.99 \\
\hline 69.94 & 16.83 & 599 & 30 & -23.50 & 17.30 & 843 & 82 & 53.47 \\
\hline 136.78 & 15.62 & -427 & 34 & 51.54 & 14.58 & 1514 & 88 & -151.90 \\
\hline 52.02 & 14.02 & 927 & 65 & 53.07 & 13.69 & 1069 & 33 & 69.42 \\
\hline 130.53 & 14.16 & -1055 & 23 & 46.30 & 12.91 & 1824 & 75 & 69.84 \\
\hline 44.31 & 11.77 & 2224 & 35 & 168.37 & 12.45 & 651 & 59 & -111.05 \\
\hline-98.78 & 12.18 & -192 & 67 & 45.01 & 10.88 & 1924 & 63 & 69.38 \\
\hline 161.58 & 11.33 & 1019 & 80 & 165.17 & 11.20 & 522 & 67 & -145.88 \\
\hline 70.14 & 9.91 & 250 & 8 & 70.75 & 9.60 & 401 & 9 & -93.48 \\
\hline 70.44 & 8.18 & 697 & 7 & 120.28 & 7.58 & -808 & 65 & 70.67 \\
\hline-123.98 & 5.78 & -75 & 71 & 122.83 & 4.08 & -1254 & 101 & -115.68 \\
\hline 123.62 & 2.92 & -1597 & 100 & 138.17 & 2.91 & -57 & 42 & -2.77 \\
\hline 143.27 & 1.86 & -71 & 43 & -19.66 & 2.45 & 252 & 67 & 169.18 \\
\hline-39.08 & 0.98 & 596 & 82 & -123.43 & 0.18 & -148 & 57 & -23.86 \\
\hline-131.52 & -1.38 & -248 & 40 & -40.07 & -1.12 & 30 & 132 & -26.67 \\
\hline 49.60 & -3.47 & 795 & 56 & 51.48 & -3.60 & 620 & 86 & -114.22 \\
\hline 58.48 & -5.33 & 911 & 42 & 59.22 & -5.42 & 1018 & 75 & 60.03 \\
\hline 75.08 & -5.35 & 470 & 56 & 54.84 & -5.96 & 806 & 27 & 63.07 \\
\hline 69.97 & -5.66 & 301 & 93 & 54.64 & -6.65 & 757 & 22 & -118.67 \\
\hline 56.50 & -9.83 & 1233 & 39 & 57.12 & -9.97 & 1428 & 95 & 57.88 \\
\hline 153.81 & -10.65 & -69 & 0 & -142.42 & -11.33 & 433 & 20 & -133.58 \\
\hline 115.45 & -11.88 & 314 & 40 & 119.12 & -12.49 & 254 & 8 & -128.95 \\
\hline 115.35 & -12.85 & 67 & 69 & 149.92 & -12.58 & -781 & 104 & -143.55 \\
\hline
\end{tabular}


Table 3 - continued

\begin{tabular}{|c|c|c|c|c|c|c|c|c|c|c|c|c|c|c|c|}
\hline Lon. $^{a}$ & Lat. $^{a}$ & $z_{r}, \mathrm{~m}$ & Error, $\mathrm{m}$ & Lon. $^{a}$ & Lat. ${ }^{a}$ & $z_{r}, \mathrm{~m}$ & Error, $\mathrm{m}$ & Lon. $^{a}$ & Lat. $^{a}$ & $z_{r}, \mathrm{~m}$ & Error, $\mathrm{m}$ & Lon. $^{a}$ & Lat. $^{a}$ & $z_{r}, \mathrm{~m}$ & Error, $\mathrm{m}$ \\
\hline 90.80 & -13.83 & -10 & 18 & 115.55 & -13.78 & -656 & 56 & 118.43 & -13.52 & -439 & 48 & 154.11 & -14.35 & -371 & 37 \\
\hline-119.17 & -14.27 & 271 & 54 & -79.07 & -13.58 & 218 & 38 & 108.15 & -14.95 & -157 & 41 & 113.48 & -15.38 & -319 & 19 \\
\hline 114.01 & -15.40 & -39 & 11 & 150.62 & -14.80 & -322 & 176 & 153.44 & -15.05 & -168 & 16 & 153.81 & -14.86 & -332 & 21 \\
\hline-136.10 & -15.03 & 9 & 42 & -112.08 & -14.73 & 60 & 39 & 89.32 & -16.42 & -380 & 59 & 114.22 & -15.59 & -294 & 10 \\
\hline-168.52 & -16.27 & -505 & 76 & -160.98 & -17.47 & 487 & 46 & 112.54 & -17.80 & 970 & 3 & -176.35 & -18.32 & 653 & 0 \\
\hline-158.67 & -17.53 & 313 & 27 & -141.43 & -18.47 & 168 & 60 & 38.26 & -18.72 & 40 & 234 & -176.44 & -18.57 & 706 & 0 \\
\hline-81.55 & -18.98 & 418 & 70 & 162.32 & -20.01 & 44 & 50 & 162.74 & -19.90 & 129 & 47 & -175.94 & -19.52 & 299 & 0 \\
\hline-113.75 & -20.30 & -203 & 71 & 97.20 & -20.72 & -288 & 27 & -37.44 & -21.48 & 128 & 45 & 37.81 & -22.14 & 440 & 77 \\
\hline 178.55 & -21.92 & -907 & 98 & -147.63 & -21.70 & 347 & 19 & -79.07 & -21.55 & 365 & 29 & -38.54 & -22.27 & 592 & 54 \\
\hline-37.32 & -21.66 & 146 & 43 & 10.28 & -23.15 & -219 & 54 & 10.80 & -23.00 & -51 & 62 & 106.39 & -23.22 & -183 & 6 \\
\hline 106.53 & -23.27 & -472 & 18 & 111.59 & -22.70 & -273 & 21 & 164.95 & -23.00 & 418 & 99 & -117.83 & -23.27 & 336 & 67 \\
\hline-38.58 & -22.53 & 717 & 52 & 10.32 & -23.60 & -315 & 57 & 36.45 & -24.02 & 1571 & 78 & 166.04 & -24.32 & 114 & 55 \\
\hline 170.83 & -23.90 & -510 & 61 & 171.80 & -23.53 & -1145 & 79 & 57.45 & -24.57 & 364 & 50 & 104.20 & -25.05 & 564 & 41 \\
\hline 107.79 & -25.33 & -340 & 5 & 11.39 & -26.20 & -227 & 44 & 11.99 & -25.95 & -56 & 59 & -36.66 & -26.22 & 21 & 32 \\
\hline-36.36 & -26.23 & -38 & 36 & 11.42 & -26.67 & -247 & 43 & 11.54 & -26.55 & -199 & 47 & 58.17 & -26.93 & -359 & 45 \\
\hline 110.11 & -27.08 & -636 & 10 & 155.87 & -27.10 & -398 & 114 & -88.82 & -27.07 & 429 & 18 & -45.60 & -27.29 & 378 & 140 \\
\hline-45.34 & -27.40 & 78 & 137 & 156.10 & -27.78 & -88 & 134 & -106.93 & -27.93 & 314 & 58 & -96.32 & -28.02 & 570 & 20 \\
\hline-45.41 & -27.54 & 113 & 131 & 37.15 & -29.49 & -216 & 64 & 112.53 & -29.26 & -266 & 21 & 13.10 & -30.07 & 60 & 87 \\
\hline 33.38 & -30.27 & 931 & 61 & 33.68 & -30.38 & 892 & 59 & 111.52 & -29.70 & 25 & 49 & 113.60 & -30.28 & 263 & 12 \\
\hline 176.00 & -29.50 & -317 & 101 & 176.77 & -29.92 & -658 & 59 & 13.41 & -31.16 & 138 & 73 & 13.86 & -31.21 & 138 & 87 \\
\hline 61.87 & -31.48 & 296 & 51 & 62.60 & -31.35 & 687 & 27 & 113.41 & -31.23 & -26 & 14 & 13.48 & -31.72 & 161 & 71 \\
\hline 13.93 & -31.73 & 241 & 81 & 32.49 & -31.81 & -24 & 115 & 61.50 & -31.54 & 836 & 44 & 111.40 & -32.48 & 2 & 13 \\
\hline 111.68 & -32.49 & 66 & 13 & 113.16 & -32.10 & 376 & 7 & 113.81 & -31.64 & 36 & 22 & 14.35 & -32.53 & 386 & 94 \\
\hline 31.26 & -33.37 & 61 & 106 & 31.94 & -33.03 & 559 & 103 & 62.08 & -33.09 & -40 & 36 & 102.75 & -32.75 & 325 & 25 \\
\hline 103.50 & -33.02 & 290 & 77 & 109.32 & -32.76 & -104 & 13 & 110.31 & -32.51 & 9 & 8 & 16.00 & -34.08 & 194 & 36 \\
\hline 96.02 & -33.80 & -81 & 45 & 105.92 & -34.18 & -323 & 43 & 28.48 & -35.49 & 126 & 108 & 29.09 & -35.37 & -25 & 92 \\
\hline 111.06 & -35.35 & 123 & 13 & 112.04 & -35.37 & -8 & 9 & 73.67 & -35.77 & 224 & 73 & 111.49 & -35.84 & 218 & 2 \\
\hline 111.59 & -35.66 & 38 & 6 & 76.38 & -36.85 & 743 & 79 & 78.52 & -37.25 & 668 & 42 & 133.98 & -36.89 & -933 & 132 \\
\hline 134.63 & -37.12 & -991 & 166 & 87.65 & -37.93 & -51 & 36 & 63.97 & -39.75 & 271 & 54 & -132.88 & -40.60 & -98 & 15 \\
\hline-96.08 & -42.73 & -263 & 55 & -104.43 & -43.77 & 185 & 59 & -110.62 & -44.58 & -161 & 26 & -45.13 & -55.37 & -764 & 16 \\
\hline-44.83 & -56.01 & -235 & 11 & -44.56 & -56.54 & -29 & 17 & 11.48 & -62.49 & 409 & 4 & 11.86 & -61.99 & 470 & 4 \\
\hline 11.11 & -63.00 & 147 & 4 & 10.46 & -63.88 & -112 & 7 & 10.62 & -63.65 & -19 & 6 & 15.41 & 74.31 & 471 & 184 \\
\hline 9.86 & 73.17 & 1190 & 146 & 13.46 & 72.09 & 948 & 187 & -12.00 & 71.94 & 985 & 76 & 15.91 & 70.38 & 899 & 145 \\
\hline
\end{tabular}




\section{Hotspots and Amagmatic Swells}

Table 4: 64 locations of Neogene intraplate hotspot volcanism.

\begin{tabular}{|c|c|c|c|c|}
\hline Name & Location & Lon. $^{a}$ & Lat. $^{a}$ & Reference \\
\hline Afar & Ethiopia & 43 & 10 & 60 \\
\hline Anahim & British Columbia & -124 & 53 & 61 \\
\hline Anatolia & Turkey & 34 & 39 & 62 \\
\hline Ankaratra & Madagascar & 47 & -20 & 63 \\
\hline Ascension & S Atlantic Ocean & -14 & -8 & 60 \\
\hline Atherton & Queensland & 144 & -20 & 64 \\
\hline Azores & C Atlantic Ocean & -28 & 39 & 60 \\
\hline Balleny & SW Pacific Ocean & 163 & -67 & 60 \\
\hline Bermuda & C Atlantic Ocean & -67 & 33 & 60 \\
\hline Borborema & NE Brazil & -37 & -7 & 65 \\
\hline Bouvet & S Atlantic Ocean & 2 & -54 & 60 \\
\hline Bowie & NE Pacific Ocean & -135 & 53 & 60 \\
\hline Cameroon & Cameroon & 9 & 4 & 60 \\
\hline Canary & C Atlantic Ocean & -20 & 28 & 60 \\
\hline Cape Verde & C Atlantic Ocean & -20 & 14 & 60 \\
\hline Caroline & W Pacific Ocean & 164 & 5 & 60 \\
\hline Carnarvon & Queensland & 147 & -25 & 66 \\
\hline Cobb & NE Pacific Ocean & -130 & 46 & 60 \\
\hline Comores & Mozambique Channel & 43 & -12 & 60 \\
\hline Crozet & SW Indian Ocean & 50 & -45 & 60 \\
\hline Darfur & Sudan & 24 & 13 & 60 \\
\hline Discovery & S Atlantic Ocean & 0 & -42 & 60 \\
\hline East Australia & Victoria & 143 & -38 & 60 \\
\hline Easter & SE Pacific Ocean & -110 & -27 & 60 \\
\hline Eifel & Germany & 7 & 50 & 60 \\
\hline Fernando & C Atlantic Ocean & -32 & -4 & 60 \\
\hline Galapagos & E Pacific Ocean & -92 & 0 & 60 \\
\hline Gough & S Atlantic Ocean & -10 & -40 & 67 \\
\hline Guadalupe & E Pacific Ocean & -113 & 27 & 60 \\
\hline Hawaii & C Pacific Ocean & -156 & 20 & 60 \\
\hline Heard & SW Indian Ocean & 73 & -53 & 68 \\
\hline Hoggar & Algeria & 6 & 23 & 60 \\
\hline Iceland & N Atlantic Ocean & -20 & 65 & 60 \\
\hline Jan Mayen & N Atlantic Ocean & -8 & 71 & 60 \\
\hline Juan Fernandez & SE Pacific Ocean & -83 & -34 & 60 \\
\hline Kerguelen & SW Indian Ocean & 69 & -49 & 60 \\
\hline Lord Howe & Tasman Sea & 159 & -33 & 60 \\
\hline Louisville & S Pacific Ocean & -141 & -51 & 60 \\
\hline Macdonald & C Pacific Ocean & -140 & -30 & 60 \\
\hline Marion & SW Indian Ocean & 38 & -47 & 60 \\
\hline Marqueses & C Pacific Ocean & -138 & -10 & 60 \\
\hline Meteor & S Atlantic Ocean & 1 & -52 & 60 \\
\hline Mount d'Ambre & Madagascar & 49 & -13 & 69 \\
\hline New England & C Atlantic Ocean & -32 & 28 & 60 \\
\hline Pitcairn & C Pacific Ocean & -130 & -26 & 60 \\
\hline Rahat & W Arabia & 40 & 23 & 70 \\
\hline Raton & Colorado & -104 & 37 & 60 \\
\hline Reunion & W Indian Ocean & 56 & -21 & 60 \\
\hline Samoa & W Pacific Ocean & -170 & -14 & 60 \\
\hline San Felix & SE Pacific Ocean & -80 & -26 & 60 \\
\hline Semporna & Borneo & 118 & 5 & 71 \\
\hline Shamah & Jordan & 36 & 33 & 70 \\
\hline Sierra Madre & Mexico & -102 & 20 & 72 \\
\hline St Helena & S Atlantic Ocean & -20 & -17 & 60 \\
\hline St Paul & C Indian Ocean & 78 & -38 & 73 \\
\hline Socorro & E Pacific Ocean & -111 & 19 & 60 \\
\hline Tasmanid & Tasman Sea & 156 & -39 & 60 \\
\hline Tahiti & C Pacific Ocean & -150 & -18 & 60 \\
\hline Tibesti & Chad & 17 & 21 & 60 \\
\hline Trindade & S Atlantic Ocean & -29 & -20 & 60 \\
\hline Tristan & S Atlantic Ocean & -12 & -37 & 60 \\
\hline Vema & S Atlantic Ocean & 4 & -33 & 60 \\
\hline Victoria & Victoria & 145 & -35 & 74 \\
\hline Yellowstone & Wyoming & -111 & 44 & 60 \\
\hline
\end{tabular}

In decimal degrees 
Table 5: 9 amagmatic topographic swells with approximately radial drainage patterns.

\begin{tabular}{lcrr}
\hline Name & Location & Lon. $^{a}$ & Lat. $^{a}$ \\
\hline Guiana Highlands & Venezuela & -64 & 5 \\
Mantiqueira Mountains & SE Brazil & -45 & -21 \\
Atlas Mountains & Morocco & -5 & 32 \\
Fouta Djallon & Guinea & -9 & 8 \\
Albertine Rift Mountains & Rwanda & 29 & -2 \\
Bié Dome & Angola & 16 & -13 \\
Namibian Dome & Namibia & 17 & -22 \\
Drakensberg Mountains & South Africa & 28 & -28 \\
Hardangervidda & Norway & 9 & 61 \\
\hline${ }^{a}$ In decimal degrees & & &
\end{tabular}




\section{Spherical Harmonic Coefficients}

Table 6: Fully normalised spherical harmonic coefficients for $l=30$ model shown in Figure 4a of main text.

\begin{tabular}{|c|c|c|c|c|c|c|}
\hline$l$ & $m$ & $f_{l m}, \mathrm{~m}$ & $f_{l-m}, \mathrm{~m}$ & $l$ & $m$ & $f_{l m}, \mathrm{~m}$ \\
\hline 0 & 0 & 0.0 & 0.0 & 15 & 4 & -21.2 \\
\hline 1 & 0 & -163.0 & 0.0 & 15 & 5 & -40.5 \\
\hline 1 & 1 & 108.8 & -92.4 & 15 & 6 & -22.3 \\
\hline 2 & 0 & 40.6 & 0.0 & 15 & 7 & -32.5 \\
\hline 2 & 1 & 162.7 & -169.8 & 15 & 8 & 2.6 \\
\hline 2 & 2 & 263.7 & 248.0 & 15 & 9 & -100.5 \\
\hline 3 & 0 & 280.0 & 0.0 & 15 & 10 & -26.8 \\
\hline 3 & 1 & 59.3 & -182.0 & 15 & 11 & -10.6 \\
\hline 3 & 2 & -139.9 & 118.5 & 15 & 12 & 21.1 \\
\hline 3 & 3 & -78.1 & 142.9 & 15 & 13 & 23.0 \\
\hline 4 & 0 & 134.4 & 0.0 & 15 & 14 & 8.5 \\
\hline 4 & 1 & -34.1 & -42.5 & 15 & 15 & 59.6 \\
\hline 4 & 2 & 31.8 & 306.7 & 16 & 0 & 16.1 \\
\hline 4 & 3 & -31.4 & -145.7 & 16 & 1 & 62.1 \\
\hline 4 & 4 & -24.6 & 38.2 & 16 & 2 & -31.4 \\
\hline 5 & 0 & -9.5 & 0.0 & 16 & 3 & -25.4 \\
\hline 5 & 1 & -70.9 & -102.3 & 16 & 4 & 39.6 \\
\hline 5 & 2 & -209.0 & 109.4 & 16 & 5 & 81.7 \\
\hline 5 & 3 & -57.7 & -104.7 & 16 & 6 & -74.2 \\
\hline 5 & 4 & 13.6 & -119.6 & 16 & 7 & 59.9 \\
\hline 5 & 5 & 174.8 & -45.5 & 16 & 8 & 24.7 \\
\hline 6 & 0 & -1.7 & 0.0 & 16 & 9 & 19.5 \\
\hline 6 & 1 & -23.3 & -184.8 & 16 & 10 & 46.4 \\
\hline 6 & 2 & -69.5 & 36.7 & 16 & 11 & 48.9 \\
\hline 6 & 3 & 77.5 & -147.0 & 16 & 12 & -99.4 \\
\hline 6 & 4 & -112.2 & -49.0 & 16 & 13 & -0.6 \\
\hline 6 & 5 & 107.7 & 151.4 & 16 & 14 & -110.9 \\
\hline 6 & 6 & -202.1 & -51.5 & 16 & 15 & -15.8 \\
\hline 7 & 0 & -102.9 & 0.0 & 16 & 16 & 17.2 \\
\hline 7 & 1 & 55.7 & -110.2 & 17 & 0 & -5.9 \\
\hline 7 & 2 & 4.6 & 68.8 & 17 & 1 & 67.0 \\
\hline 7 & 3 & 142.8 & -2.9 & 17 & 2 & 51.2 \\
\hline 7 & 4 & 23.7 & -331.1 & 17 & 3 & -67.2 \\
\hline 7 & 5 & -24.5 & 157.3 & 17 & 4 & -25.3 \\
\hline 7 & 6 & 100.8 & -31.1 & 17 & 5 & 4.6 \\
\hline 7 & 7 & -108.7 & 37.0 & 17 & 6 & -81.0 \\
\hline 8 & 0 & -158.9 & 0.0 & 17 & 7 & 27.7 \\
\hline 8 & 1 & -14.9 & 9.8 & 17 & 8 & -47.0 \\
\hline 8 & 2 & -7.0 & 143.9 & 17 & 9 & 67.1 \\
\hline 8 & 3 & 62.8 & 9.6 & 17 & 10 & 11.7 \\
\hline 8 & 4 & -52.8 & -28.2 & 17 & 11 & 27.1 \\
\hline 8 & 5 & -45.5 & 24.8 & 17 & 12 & 59.7 \\
\hline 8 & 6 & 5.6 & -62.8 & 17 & 13 & -4.7 \\
\hline 8 & 7 & 5.2 & 71.8 & 17 & 14 & 12.2 \\
\hline 8 & 8 & 42.5 & -102.9 & 17 & 15 & 66.0 \\
\hline 9 & 0 & 32.1 & 0.0 & 17 & 16 & -63.8 \\
\hline 9 & 1 & -2.5 & -147.3 & 17 & 17 & 33.7 \\
\hline 9 & 2 & -13.3 & 129.8 & 18 & 0 & 82.6 \\
\hline 9 & 3 & 45.9 & 128.6 & 18 & 1 & 53.9 \\
\hline 9 & 4 & -74.1 & -24.0 & 18 & 2 & -9.7 \\
\hline 9 & 5 & 16.0 & -50.6 & 18 & 3 & -72.9 \\
\hline 9 & 6 & 194.9 & 36.3 & 18 & 4 & -5.6 \\
\hline 9 & 7 & 31.2 & 84.1 & 18 & 5 & -7.4 \\
\hline 9 & 8 & -50.2 & -87.4 & 18 & 6 & -11.3 \\
\hline 9 & 9 & 27.8 & -20.1 & 18 & 7 & 6.6 \\
\hline 10 & 0 & 24.2 & 0.0 & 18 & 8 & -50.4 \\
\hline 10 & 1 & 119.5 & 70.8 & 18 & 9 & 1.0 \\
\hline 10 & 2 & -107.1 & -61.5 & 18 & 10 & 33.4 \\
\hline 10 & 3 & 68.8 & -31.5 & 18 & 11 & -9.8 \\
\hline 10 & 4 & -155.4 & -100.7 & 18 & 12 & -9.8 \\
\hline 10 & 5 & -31.2 & 72.3 & 18 & 13 & 12.0 \\
\hline 10 & 6 & -54.7 & 5.5 & 18 & 14 & -68.3 \\
\hline 10 & 7 & -20.0 & 88.4 & 18 & 15 & -1.7 \\
\hline 10 & 8 & -46.8 & 16.1 & 18 & 16 & -13.4 \\
\hline 10 & 9 & 95.6 & -124.1 & 18 & 17 & -34.9 \\
\hline 10 & 10 & 72.6 & 199.5 & 18 & 18 & -3.2 \\
\hline 11 & 0 & 49.7 & 0.0 & 19 & 0 & -92.3 \\
\hline 11 & 1 & -85.3 & -41.4 & 19 & 1 & 23.6 \\
\hline 11 & 2 & -123.3 & 2.5 & 19 & 2 & 25.5 \\
\hline 11 & 3 & 156.0 & -33.7 & 19 & 3 & -6.1 \\
\hline 11 & 4 & -30.3 & -65.7 & 19 & 4 & 28.6 \\
\hline 11 & 5 & -38.0 & -116.4 & 19 & 5 & -84.6 \\
\hline 11 & 6 & 31.0 & -159.3 & 19 & 6 & 43.2 \\
\hline 11 & 7 & -34.6 & 0.8 & 19 & 7 & -35.2 \\
\hline 11 & 8 & -19.0 & 8.6 & 19 & 8 & -28.8 \\
\hline 11 & 9 & -106.9 & -49.9 & 19 & 9 & -9.7 \\
\hline 11 & 10 & 38.7 & 26.7 & 19 & 10 & 30.2 \\
\hline 11 & 11 & -83.6 & 130.2 & 19 & 11 & -61.1 \\
\hline 12 & 0 & -50.9 & 0.0 & 19 & 12 & -9.0 \\
\hline 12 & 1 & 55.7 & 34.1 & 19 & 13 & 46.7 \\
\hline 12 & 2 & 141.9 & 37.0 & 19 & 14 & -3.0 \\
\hline 12 & 3 & -53.2 & -43.3 & 19 & 15 & -41.6 \\
\hline 12 & 4 & 60.3 & 0.6 & 19 & 16 & -15.8 \\
\hline 12 & 5 & 93.5 & -28.0 & 19 & 17 & -23.2 \\
\hline 12 & 6 & 32.1 & 22.2 & 19 & 18 & -15.5 \\
\hline 12 & 7 & -90.3 & 29.0 & 19 & 19 & -29.2 \\
\hline 12 & 8 & 33.5 & -79.6 & 20 & 0 & 81.8 \\
\hline 12 & 9 & 62.7 & 73.6 & 20 & 1 & 54.5 \\
\hline 12 & 10 & -29.9 & -75.9 & 20 & 2 & 59.0 \\
\hline 12 & 11 & -52.7 & -18.0 & 20 & 3 & -52.4 \\
\hline 12 & 12 & -117.6 & -2.4 & 20 & 4 & -61.7 \\
\hline
\end{tabular}


Table 6 - continued

\begin{tabular}{|c|c|c|c|c|c|c|c|c|c|c|c|c|c|c|c|}
\hline \multirow[b]{2}{*}{ 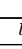 } & \multirow[b]{2}{*}{$m$} & \multirow[b]{2}{*}{$f_{l m}, \mathrm{~m}$} & \multirow[b]{2}{*}{$f_{l-m}, \mathrm{~m}$} & \multirow[b]{2}{*}{$l$} & \multirow[b]{2}{*}{$m$} & \multirow[b]{2}{*}{$f_{l m}, \mathrm{~m}$} & \multirow[b]{2}{*}{$f_{l-m}, \mathrm{~m}$} & \multirow[b]{2}{*}{$l$} & \multirow[b]{2}{*}{$m$} & \multirow[b]{2}{*}{$f_{l m}, \mathrm{~m}$} & \multirow[b]{2}{*}{$f_{l-m}, \mathrm{~m}$} & \multirow[b]{2}{*}{$l$} & \multirow[b]{2}{*}{$m$} & \\
\hline & & & & & & & & & & & & & & $f_{l m}, \mathrm{~m}$ & $f_{l-m}, \mathrm{~m}$ \\
\hline 13 & 0 & 78.6 & 0.0 & 20 & 5 & 42.1 & 19.0 & 25 & 14 & -7.8 & 28.1 & 29 & 28 & -38.5 & -13.7 \\
\hline 13 & 1 & -0.5 & -36.3 & 20 & 6 & -22.7 & 50.9 & 25 & 15 & -0.4 & -7.0 & 29 & 29 & 8.5 & -38.7 \\
\hline 13 & 2 & -16.0 & -53.6 & 20 & 7 & -10.2 & 48.9 & 25 & 16 & -11.0 & -5.2 & 30 & 0 & 14.5 & 0.0 \\
\hline 13 & 3 & -112.8 & 89.7 & 20 & 8 & -28.4 & -60.5 & 25 & 17 & 10.9 & 14.5 & 30 & 1 & -74.7 & -11.5 \\
\hline 13 & 4 & -28.0 & -27.7 & 20 & 9 & 7.2 & 0.1 & 25 & 18 & 1.7 & 2.0 & 30 & 2 & 40.8 & 10.7 \\
\hline 13 & 5 & -97.8 & -82.2 & 20 & 10 & -5.9 & -6.4 & 25 & 19 & 28.2 & 27.6 & 30 & 3 & 8.2 & -39.9 \\
\hline 13 & 6 & -29.7 & 83.7 & 20 & 11 & 46.2 & 32.4 & 25 & 20 & 14.7 & 17.3 & 30 & 4 & -78.9 & -8.0 \\
\hline 13 & 7 & 58.4 & -41.9 & 20 & 12 & 41.6 & -22.2 & 25 & 21 & -29.9 & -19.2 & 30 & 5 & -18.5 & 13.2 \\
\hline 13 & 8 & 17.4 & -27.0 & 20 & 13 & -81.1 & -72.0 & 25 & 22 & -52.6 & 20.3 & 30 & 6 & 24.9 & -41.7 \\
\hline 13 & 9 & -66.7 & -21.2 & 20 & 14 & -80.5 & 3.1 & 25 & 23 & -3.5 & 2.5 & 30 & 7 & 4.8 & -30.4 \\
\hline 13 & 10 & 8.2 & 26.8 & 20 & 15 & 37.2 & 50.8 & 25 & 24 & -36.0 & -33.9 & 30 & 8 & -3.7 & -3.1 \\
\hline 13 & 11 & 30.2 & -24.6 & 20 & 16 & 1.4 & -47.2 & 25 & 25 & -27.8 & -72.7 & 30 & 9 & 28.5 & 23.1 \\
\hline 13 & 12 & 108.7 & -139.6 & 20 & 17 & 83.9 & 1.9 & 26 & 0 & -19.8 & 0.0 & 30 & 10 & 38.8 & 7.3 \\
\hline 13 & 13 & -48.8 & 1.6 & 20 & 18 & 44.2 & 38.4 & 26 & 1 & 2.0 & 12.4 & 30 & 11 & -19.3 & -24.1 \\
\hline 14 & 0 & -43.1 & 0.0 & 20 & 19 & 15.4 & 46.6 & 26 & 2 & 37.9 & -16.2 & 30 & 12 & -11.8 & 38.0 \\
\hline 14 & 1 & -4.5 & 110.6 & 20 & 20 & -70.7 & 0.5 & 26 & 3 & 2.3 & -12.1 & 30 & 13 & 12.7 & 6.4 \\
\hline 14 & 2 & 89.2 & -115.7 & 21 & 0 & 20.3 & 0.0 & 26 & 4 & -27.2 & 22.5 & 30 & 14 & -3.6 & 18.5 \\
\hline 14 & 3 & -32.6 & -52.2 & 21 & 1 & 46.3 & 50.0 & 26 & 5 & -22.6 & 2.3 & 30 & 15 & 9.5 & -8.6 \\
\hline 14 & 4 & -73.7 & 21.3 & 21 & 2 & 16.1 & 21.1 & 26 & 6 & -19.1 & 26.3 & 30 & 16 & -25.6 & 19.3 \\
\hline 14 & 5 & -5.6 & -13.1 & 21 & 3 & -59.2 & -2.7 & 26 & 7 & 19.1 & -0.8 & 30 & 17 & 17.7 & 15.9 \\
\hline 14 & 6 & -8.8 & -21.2 & 21 & 4 & -23.2 & -9.6 & 26 & 8 & -36.5 & 19.0 & 30 & 18 & -13.2 & -29.7 \\
\hline 14 & 7 & 21.4 & -40.7 & 21 & 5 & -13.0 & 68.9 & 26 & 9 & 72.3 & 38.2 & 30 & 19 & -27.5 & -6.0 \\
\hline 14 & 8 & 66.5 & 43.9 & 21 & 6 & -9.8 & 18.6 & 26 & 10 & 16.8 & -35.6 & 30 & 20 & 39.6 & -8.4 \\
\hline 14 & 9 & -10.9 & -36.3 & 21 & 7 & 73.9 & -10.2 & 26 & 11 & 0.5 & 13.1 & 30 & 21 & 21.9 & 40.2 \\
\hline 14 & 10 & 61.1 & 92.4 & 21 & 8 & 14.8 & -56.8 & 26 & 12 & 16.6 & -0.6 & 30 & 22 & -13.3 & -8.6 \\
\hline 14 & 11 & 103.0 & -30.8 & 21 & 9 & 9.8 & 12.9 & 26 & 13 & 1.9 & -12.0 & 30 & 23 & 8.7 & -1.4 \\
\hline 14 & 12 & 52.3 & 33.5 & 21 & 10 & -18.6 & 45.9 & 26 & 14 & 10.0 & 36.4 & 30 & 24 & -47.5 & 13.6 \\
\hline 14 & 13 & -70.8 & 20.4 & 21 & 11 & 37.0 & -4.8 & 26 & 15 & -3.1 & -8.9 & 30 & 25 & 35.5 & 3.6 \\
\hline 14 & 14 & 46.9 & -134.1 & 21 & 12 & 29.8 & -46.4 & 26 & 16 & -1.0 & -18.3 & 30 & 26 & -4.6 & -1.5 \\
\hline 15 & 0 & 29.6 & 0.0 & 21 & 13 & -70.8 & 65.5 & 26 & 17 & -18.6 & -14.5 & 30 & 27 & -47.4 & -13.9 \\
\hline 15 & 1 & 73.6 & 1.5 & 21 & 14 & 30.3 & 7.5 & 26 & 18 & 7.4 & 4.8 & 30 & 28 & 2.8 & -21.9 \\
\hline 15 & 2 & -91.1 & 56.7 & 21 & 15 & 20.7 & -55.1 & 26 & 19 & -15.7 & 8.7 & 30 & 29 & 1.9 & 19.1 \\
\hline 15 & 3 & 7.1 & -20.0 & 21 & 16 & -5.7 & 41.2 & 26 & 20 & 5.8 & -4.3 & 30 & 30 & 21.1 & 19.0 \\
\hline
\end{tabular}

